\title{
Effects of food availability on sediment reworking in Abra ovata and A. nitida*
}

\author{
Olivier Maire ${ }^{1, * *}$, Jean Claude Duchêne ${ }^{1}$, Rutger Rosenberg $^{2}$, \\ Joël Braga de Mendonça Jr. ${ }^{1}$, Antoine Grémare ${ }^{1}$ \\ ${ }^{1}$ Université Pierre et Marie Curie-Paris, UMR 7621, 66650 Banyuls-sur-mer, France; \\ CNRS, UMR 7621, 6650 Banyuls-sur-mer, France \\ ${ }^{2}$ Department of Marine Ecology, Göteborg University Kristineberg Marine Research Station, Kristineberg, \\ 45034 Fiskebäckskil, Sweden
}

\begin{abstract}
We used a new experimental approach involving thin aquaria, luminophores, time lapse photography and image analysis to assess sediment reworking in 2 closely related bivalves, Abra ovata and A. nitida. The method proved efficient based on the highly significant correlation between the concentrations of luminophores assessed using image analysis and direct counting of sediment slices. A. ovata and A. nitida exhibited different sediment reworking behaviours. A. ovata remained immobile within the sediment and transferred luminophores within the sediment through its siphonal activity, which resulted in the creation of typical inverse conical structures. A. nitida moved within the sediment and reworked a thinner sediment layer. Both A. ovata and A. nitida were characterised as biodiffusers. Biodiffusion coefficients $\left(D_{\mathrm{b}}\right)$ were maximal at intermediate food concentration in A. ovata and at high food concentration in A. nitida. This new approach allowed assessment of the effects of spatial scale and vertical grid size on the computation of $D_{\mathrm{b}}$. In both species $D_{\mathrm{b}}$ decreased with spatial scale up to $3.750 \mathrm{~cm}$ and then remained constant. It is suggested that this pattern partly resulted from heterogeneity linked to: (1) the mode of sediment reworking (A. ovata) and (2) the relative proportion of reworked sediment surface (A. nitida). Vertical grid size $>0.250 \mathrm{~cm}$ resulted in a significant overestimation of $D_{\mathrm{b}}$ in $A$. nitida, due to the low thickness of the sediment layer reworked by this species. The implications of these results on the main characteristics (duration, spatial scale, vertical grid size) of classical luminophore experiments are discussed.
\end{abstract}

KEY WORDS: Sediment reworking · Image analysis · Food availability · Scaling $\cdot$ Luminophores · Abra ovata $\cdot$ Abra nitida

\section{INTRODUCTION}

Benthic infaunal organisms, through their activity of burrowing, feeding, defecation and locomotion induce sediment reworking that affects the physical, chemical and geotechnical properties of the sediment column (Gray 1974, Rhoads 1974, Aller 1982, Rhoads \& Boyer 1982, Meadows \& Meadows 1991, Gilbert et al. 1995, Rowden et al. 1998, Lohrer et al. 2004). Biogenic sediment reworking affects, in particular, the fluxes of oxygen, nutrients, contaminants and pollutants and, more generally, the transfer and the mineralisation of organic matter at the water-sediment interface (Lee \&
Swartz 1980, Aller 1982, 1994, Aller \& Yingst 1985, Andersen \& Kristensen 1991, Furukawa et al. 2001, Mermillod-Blondin et al. 2005). Analysis and quantification of sediment reworking processes are considered key points in understanding benthic ecosystem functioning (Biles et al. 2002, Solan et al. 2004a). A better understanding of sediment reworking requires the study of dominant species that are liable to induce particular sediment reworking patterns depending on their behaviour and response to changes in biotic and abiotic environmental factors (Gérino 1990, Biles et al. 2002, Ouellette et al. 2004).

Several experimental techniques involving natural or artificial tracers (e.g. radionuclides, glass beads, 
metal-doped sediment, chlorophyll $a$, luminophores) have been used to estimate sediment reworking by benthic fauna (Robbins 1982, Robbins et al. 1984, Krezoski et al. 1984, Smith et al. 1986, White et al. 1987, Sharma et al. 1987, Sun et al. 1991, Wheatcroft 1992, Wheatcroft et al. 1994, Olmez et al. 1994, Gérino et al. 1998). These tracers are indicative of sediment reworking occurring at different timescales. Luminophores (i.e. fluorescent particles) have been widely used in laboratory (Mahaut \& Graf 1987, Gérino et al. 1998, Ouellette et al. 2004, Mermillod-Blondin et al. 2005) and in situ experiments (Mahaut \& Graf 1987, Gérino 1990, Gérino et al. 1994, 1998, Biles et al. 2002, Mugnai et al. 2003, Solan et al. 2004b). Experiments classically consist of spreading luminophores at the surface of experimental sediment cores containing test organisms at time 0 and then incubating those cores for a known amount of time. At the end of the experiments, the cores are sliced horizontally and the vertical profiles of luminophore concentration assessed. The profiles are fitted to mathematical models that allow computation of coefficients characterising the intensity of sediment reworking. The main potential drawbacks of those approaches are: (1) the lack of a dynamic view of sediment reworking, since the cores are destroyed for the assessment of luminophore profiles, (2) the vertical resolution of the luminophore profile, which is limited by the minimal thickness of the sliced sediment layer (i.e. roughly $0.5 \mathrm{~cm}$ ), (3) the impossibility of assessing sediment reworking rates at a spatial scale smaller than the experimental core, (4) the time requested to carry out the processing of the cores and the counting of the luminophores and (5) the possible mixing of luminophores between adjacent sediment layers during slicing, which may lead to an overestimation of sediment reworking (Berg et al. 2001).

To overcome these drawbacks, time-lapse photography, thin aquaria, or sediment profiling, allowing the monitoring of a vertical plan of the sediment column, and automated image analysis technique have recently been introduced. Gilbert et al. (2003) used a combination of these techniques to study sediment reworking induced by benthic communities originating from the Gullmarsfjord and the Skagerrak. Solan et al. (2004b) used time-lapse recording to assess in situ sediment reworking rates in the Gullmarsfjord. However, to our knowledge, such an approach has not been used either to assess sediment reworking rates of individual species or to assess the impact of food availability on sediment reworking rates. During the last $10 \mathrm{yr}$ considerable expertise in imaging marine organisms and populations has been developed for assessing, e.g. larval behaviour (Duchêne \& Nozais 1994, Duchêne et al. 2000, Duchêne \& Queiroga 2001, Duchêne 2004) and, more recently, feeding behaviour of both suspen- sion (Jordana et al. 2000) and deposit feeders (Hollertz \& Duchêne 2001, Grémare et al. 2004).

The aims of the present study were thus: (1) to combine the use of thin aquaria, luminophores and automated image analysis techniques to infer temporal changes in sediment reworking rates, (2) to describe sediment reworking in Abra ovata and A. nitida, 2 closely related bivalves with different feeding ethology and functional responses, (3) to assess the effects of changes in organic matter availability on sediment reworking rates and (4) to assess the effects of spatial and temporal scales on the computation of sediment reworking rates.

\section{MATERIALS AND METHODS}

Bivalve collection and maintenance. Abra ovata and A. nitida are deposit-feeding bivalves that live buried a few centimetres below the sediment and feed at the water-sediment interface using their inhalant siphon (Guelorget \& Mayere 1981, Wikander 1981).

Abra ovata is a typical species of sandy mud in NW Mediterranean lagoons, where it can be found in densities of up to several thousand individuals per square metre (Guelorget \& Mayere 1981). A. ovata were hand collected in July 2004, at depths of $<1 \mathrm{~m}$ on the north side of the Lapalme Lagoon (NW Mediterranean). Water temperature was $20^{\circ} \mathrm{C}$ and water salinity 6 PSU. Bivalves were kept for $15 \mathrm{~d}$ at the Observatoire Océanologique de Banyuls sur Mer (France) in natural sediment and well-aerated lagoon seawater. Salinity was then progressively increased to 20 PSU. At the end of July, animals were packed in sealed, refrigerated boxes filled with $\mathrm{O}_{2}$ saturated water and brought to the Kristineberg Marine Research Station (Sweden), where they were kept in tanks with flow-through surface seawater $\left(20^{\circ} \mathrm{C}, 24 \mathrm{PSU}\right)$ and natural sediment from the Gullmarsfjord (Sweden).

Abra nitida is abundant in muddy sediments in the Skagerrak and occurs in densities of up to several thousand individuals per square metre (Josefson 1982). The bivalves were collected in August 2004 in the Gullmarsfjord between $80 \mathrm{~m} \quad\left(58^{\circ} 14^{\prime} 38^{\prime \prime} \mathrm{N}\right.$, $\left.11^{\circ} 31^{\prime} 00^{\prime \prime} \mathrm{E}\right)$ and $109 \mathrm{~m}\left(58^{\circ} 17^{\prime} 18^{\prime \prime} \mathrm{N}, 11^{\circ} 30^{\prime} 39^{\prime \prime} \mathrm{E}\right)$ using a Waren dredge. The bivalves were kept at the Kristineberg Marine Research Station in tanks containing natural sediment flushed with deep seawater $\left(8^{\circ} \mathrm{C}\right.$, 35 PSU). In addition, a batch of bivalves was progressively adapted to a temperature of $15^{\circ} \mathrm{C}$. The 2 species were fed every other day with crushed Tetramin fish food. Before each experiment, specimens were measured to the nearest millimetre. The total lengths of the shells of $A$. ovata and A. nitida used during the experiments were between 12 and $13 \mathrm{~mm}$. 
Sediment reworking experiments. The same sediment was used for both species to better account for differences in sediment reworking by Abra ovata and A. nitida, since a similar approach has already been used by Grémare et al. (2004) to assess differences in feeding activity between these 2 species. Visual observations showed that after their deposit at the sediment surface A. ovata burrowed quickly into the Gullmarsfjord sediment and then featured a feeding behaviour similar to the one observed during preliminary studies performed with Lapalme Lagoon sediment (Maire pers. obs.). We filled 45 thin aquaria $(33 \times 17 \times 1.2 \mathrm{~cm})$ with $15 \mathrm{~cm}$ of muddy sediment (median diameter: $9.50 \mu \mathrm{m}_{\text {; }}$ organic carbon: $2.85 \%$ DW [dry weight]; nitrogen: $0.34 \%$ DW) collected in the Gullmarsfjord with a $0.05 \mathrm{~m}^{2}$ Olausson sediment corer at $83 \mathrm{~m}$ depth $\left(58^{\circ} 17^{\prime} 4^{\prime \prime} \mathrm{N}, 11^{\circ} 30^{\prime} 7^{\prime \prime} \mathrm{E}\right)$. The sediment was previously sieved through a $1 \mathrm{~mm}$ mesh to remove macrofauna. All aquaria with sediment were kept in a thermoregulated room under running seawater for a few days.

Sediment reworking was quantified by using luminophores (Mahaut \& Graf 1987). Luminophores are natural sediment particles covered by a thin layer of paint that fluoresces under ultraviolet (UV) light. The luminophores used during the present study were between 100 and $160 \mu \mathrm{m}$ in size. Preliminary studies (Maire pers. obs.) showed that both species of Abra were able to ingest luminophores. Three bivalves (corresponding to a density of 1470 ind. $\mathrm{m}^{-2}$ ) were gently deposited on the sediment surface. They usually buried themselves within a few minutes, but were replaced if they did not do so within $1 \mathrm{~h}$. After $24 \mathrm{~h}$ of acclimation, which is sufficient to insure the constancy of subsequent feeding behaviours in both species according to Grémare et al. (2004), $3 \mathrm{~g}$ of luminophores were homogeneously and gently spread on the sediment surface of each aquarium with a Pasteur pipette. Then, $2.86 \mathrm{mg} \mathrm{C} \mathrm{m}^{-2}$ of phytodetritus (Tetraselmis 3600 Premium Fresh, Reed marine culture) was simultaneously added to a first batch of 5 aquaria (Treatment A) and $28.6 \mathrm{mg} \mathrm{C} \mathrm{m}{ }^{-2}$ of Tetraselmis was added to a second batch of 5 aquaria (Treatment B); 5 other aquaria did not receive any food addition (Treatment T). Tetraselmis has already been used as a surrogate of sedimenting phytodetritus during several experimental studies (Hassler 1998, Grémare et al. 2004). The 2 concentrations used for food additions corresponded to maximal and intermediate values of the 5 concentrations used by Grémare et al. (2004) based on the gross sedimentation rates reported by Lindahl (1988) for the Gullmarsfjord and by Grémare et al. (1997) for the NW Mediterranean. These 2 concentrations were selected because they corresponded to maximal feeding activity in A. ovata and A. nitida, respectively (Grémare et al. 2004). Immediately after the luminophore input, the aquaria were placed in a stand in front of a digital camera (Olympus Camedia E10) and the 2 sides were photographed under UV light. This operation was repeated after $3,6,12,24$ and $48 \mathrm{~h}$. The UV light was produced by 2 black bulbs located in a reflective semi-cylinder placed about $10 \mathrm{~cm}$ in front of the aquarium. Camera settings were adjusted for adequate fluorescent detection, and the photographic field $(15 \times 17 \mathrm{~cm})$ resulted in a resolution superior to the luminophore size ( 1 pixel $=75 \times$ $75 \mu \mathrm{m})$. The aquaria were flushed with flow-through seawater after $3 \mathrm{~h}$ and kept in darkness during the entire experiment. Three experiments were run: 1 with Abra ovata $\left(20^{\circ} \mathrm{C}\right)$ and 2 with A. nitida (8 and $15^{\circ} \mathrm{C}$ ). In addition, we ran 3 controls without bivalves and without food addition $\left(1\right.$ at $8^{\circ} \mathrm{C}$ and 2 at $20^{\circ} \mathrm{C}$ ).

Image analysis. Images were saved in jpg format and red-green-blue (R-G-B) colour, with a size of $2240 \times 1680$ pixels, and were later assembled into an AVI film. Further analyses were performed directly from the film. Image treatments were carried out with the CVABimage software developed at the Laboratoire Océanologique de Banyuls (Duchêne \& Nozais 1994, Duchêne et al. 2000). On each image, the water-sediment interface was manually drawn. This line represented the initial reference used to calculate luminophore penetration depths. It was then flattened and transferred to the first pixel row of each pixel column. After this operation, the pixel $y$-position in the picture thus corresponded directly to its depth within the sediment. The second step consisted of assessing the proportion of each of the 3 colours (R-G-B) of the luminophore pixels and recording all corresponding points. Images were then thresholded and transformed to a binary matrix, where luminophore pixels were assigned a value of 1 and sediment pixels a value of 0 . Luminophore pixels were finally summed for each pixel line (i.e. depth), and vertical profiles of luminophore distribution were generated.

The vertical distributions of luminophores were also assessed directly in 5 aquaria selected at random. At the end of the experiments, these aquaria were frozen $\left(-20^{\circ} \mathrm{C}\right)$ and their sediment column was sliced (in $0.5 \mathrm{~cm}$ layers between 0 and $5 \mathrm{~cm}$ depth and in $1 \mathrm{~cm}$ layers between 5 and $10 \mathrm{~cm}$ depth). Sediment samples were frozen, freeze dried, dispersed over a Petri dish under UV light and photographed. Images were processed and luminophore pixels counted using the CVABimage software. The luminophore profiles thus obtained were then compared with those derived from the analysis of the photograph of the walls of the corresponding aquaria.

Quantification of sediment reworking. We used 2 crude indices of sediment reworking: (1) the maximum luminophore penetration depth (MPD), mea- 
sured as the distance between the sediment surface and the deepest luminophore pixel, and (2) the proportion of the total sediment surface that had been reworked by the bivalves (PRS). The assessment of PRS was based on the quantification of the proportion of the aquaria surface devoid of luminophores by the bivalves. These 2 parameters were directly assessed using CVABimage software.

Biodiffusion coefficients $\left(D_{\mathrm{b}}\right)$ were computed using a biodiffusive model. Based on the luminophore distribution observed at each time, from time $=3 \mathrm{~h}$ to time $=48 \mathrm{~h}, D_{\mathrm{b}}$ was computed with the 1-dimensional model given by Crank (1975):

$$
\frac{\partial^{2} C}{\partial t}=D_{\mathrm{b}} \frac{\partial^{2} C}{\partial z^{2}}
$$

A solution to Eq. (1) is:

$$
C(z, t)=\frac{M}{\sqrt{\pi D_{\mathrm{b}} t}} \exp \left(\frac{-z^{2}}{4 D_{\mathrm{b}} t}\right)
$$

Eq. (2) (Crank 1975) describes the spreading by diffusion of an amount of tracer $M$ deposited at $z=0$ and at time $=0$, assuming that $D_{\mathrm{b}}$ and $M$ remain constant and that the luminophores can move from the surface only toward depth (impermeable boundary at $z=0$ ).

The boundary conditions are:

1. Upper boundary condition: $\frac{\partial C}{\partial z}=0$ at $z=0$

2. Lower boundary condition: $C(z \rightarrow+\infty, t)=0$

$D_{\mathrm{b}}$ was estimated by convergent iterations and weighted least-squares regression of observed luminophores profiles on predicted tracer concentrations (François et al. 2002):

$$
r=\sum_{i=1}^{n} \frac{\left(\mathrm{obs}_{i}-\text { pred }_{i}\right)^{2}}{\operatorname{obs}_{i}+1}
$$

where $r$ is the sum of the residuals and $i$ is the number of sediment layers.

For each combination of aquarium and incubation duration, $D_{\mathrm{b}}$ was averaged for both sides of a given aquarium.

Effect of spatial scale on the computation of $\boldsymbol{D}_{\mathbf{b}}$. The effect of horizontal spatial scale on the computation of $D_{\mathrm{b}}$ was assessed using a bootstrap procedure. For each photograph recorded after $48 \mathrm{~h}, D_{\mathrm{b}}$ values were computed based on 100 randomly selected areas of increasing size (corresponding to rectangles delimited by the vertical length of the whole aquarium and by horizontal linear segments of $0.075,0.375,0.750,1.500$, $3.750,7.500,11.250,13.500$ and $17.000 \mathrm{~cm}$ ). When biogenic structures resulting from sediment reworking were apparent (i.e. during the experiments with Abra ovata), we also ran a direct comparison of $D_{\mathrm{b}}$ values computed based on the vertical distributions of luminophores within: (1) the whole aquarium and (2) a single biogenic structure.
The effect of vertical grid size was also assessed by computing $D_{\mathrm{b}}$ based on the photograph of the whole aquarium shot after $48 \mathrm{~h}$ of experiments. We used several vertical grid sizes: $0.052,0.105,0.247,0.502,0.750$ and $0.997 \mathrm{~cm}$ and computed the corresponding luminophore profiles, which were then fitted as described above to derive $D_{\mathrm{b}}$.

Statistical analysis. The directly measured luminophore concentrations and those derived from the photographs of the walls of the corresponding aquaria were compared using simple linear regression models. In Abra ovata, differences in MPD, PRS and $D_{\mathrm{b}}$ values between experiment durations and food treatments were assessed using 2-way ANOVAs (analysis of variance). Differences in: (1) MPD, PRS and $D_{\mathrm{b}}$ values in $A$. nitida between experiment durations, food treatments and temperatures and (2) MPD, PRS and $D_{\mathrm{b}}$ values between $A$. ovata and $A$. nitida were assessed using 3-way ANOVAs. Three-way ANOVAs were also used to assess the effects of horizontal scale and vertical grid size on $D_{\mathrm{b}}$. Data were square-root transformed to homogenise variances. Whenever appropri-
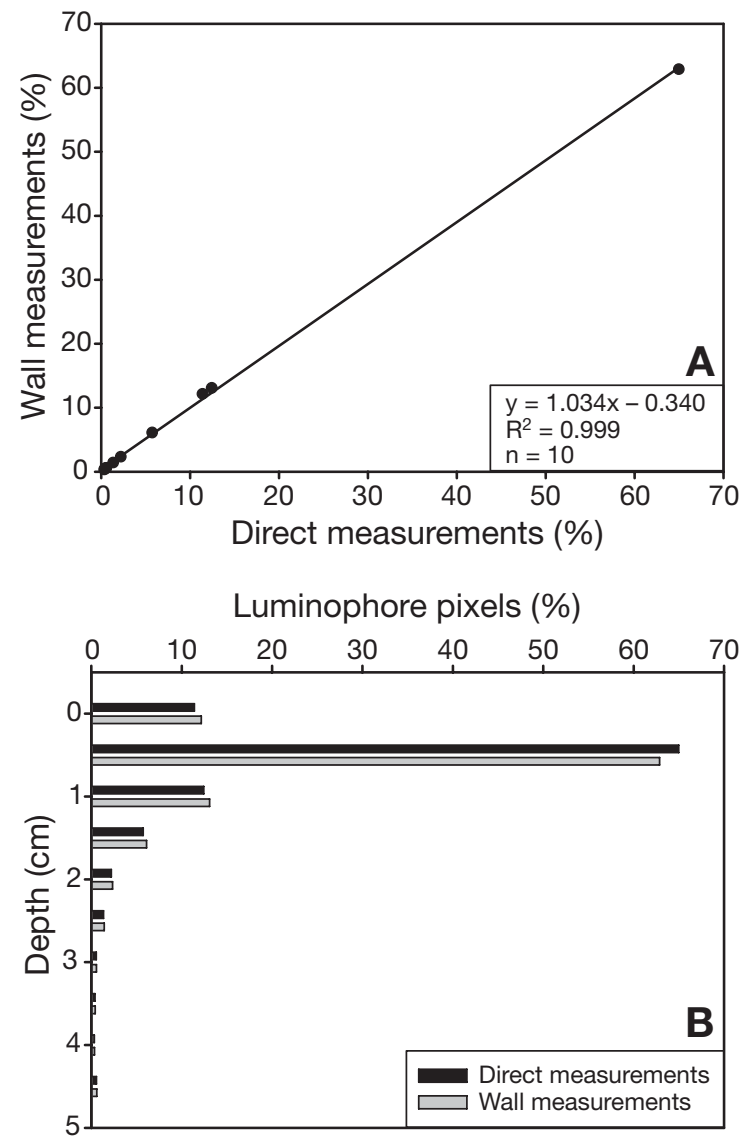

Fig. 1. Relationship between luminophore concentrations directly assessed and derived from the analysis of the photographs of the walls of the same aquarium (A), and comparison of the corresponding luminophore profiles (B) 

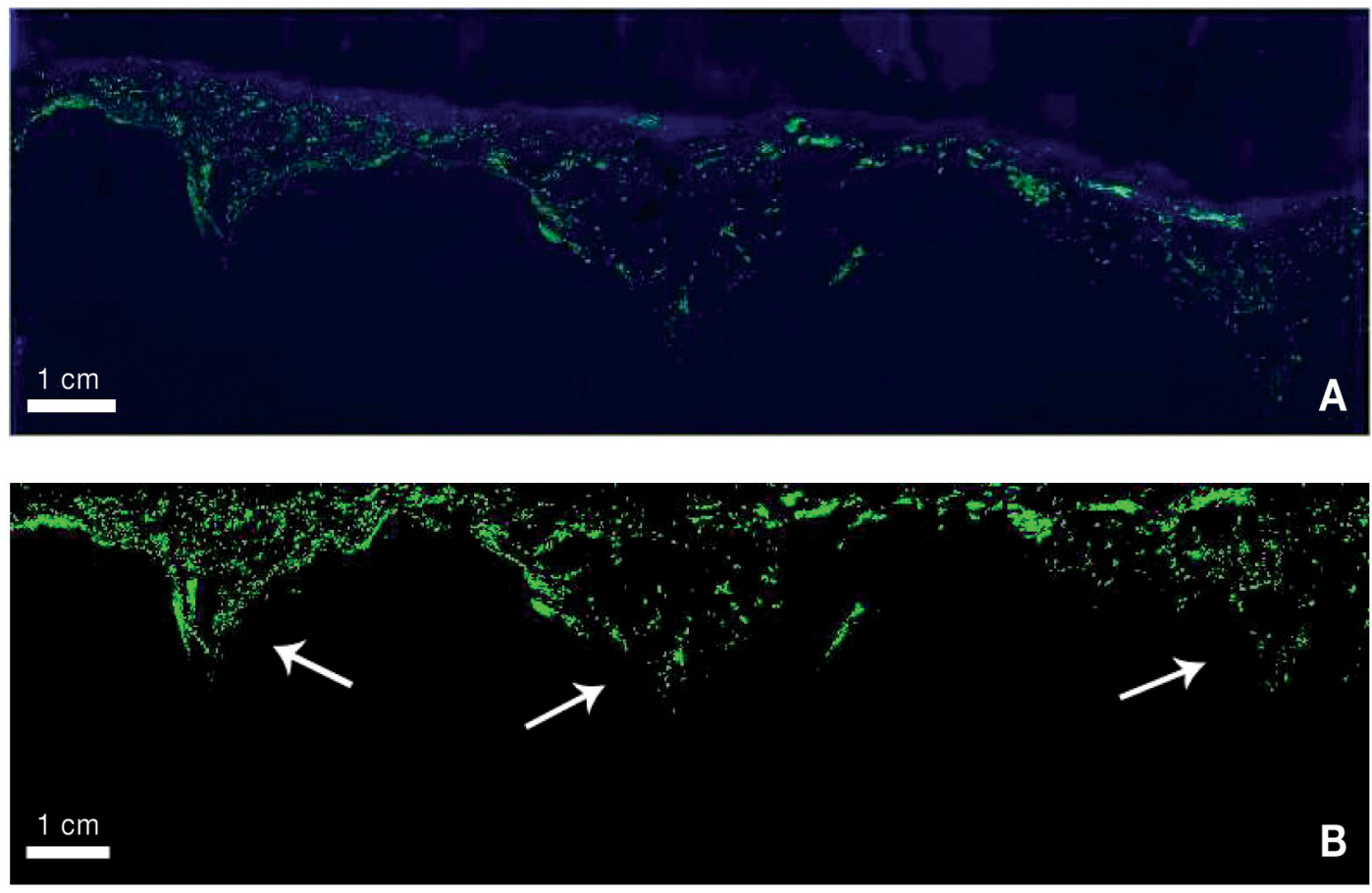

Fig. 2. Abra ovata. (A) Example of an original image with the sediment appearing in dark and luminophores in green. (B) Corresponding thresholded image with a flattened sediment-water interface. Note the occurrence of the 3 inverse conical structures characteristic of sediment reworking by individual A. ovata (white arrows)

ate, a posteriori least significant difference (LSD) tests were used to assess differences among treatments, species and temperatures.

\section{RESULTS}

\section{Comparison between the 2 methods for assessing luminophore profiles}

In all 5 tested aquaria, there was a highly significant correlation between luminophore relative concentrations based on: (1) direct measurements and (2) the analysis of the photographs of the walls of the aquaria (Fig. $1 \mathrm{~A} ; \mathrm{n}=10, \mathrm{r}^{2}>0.837, \mathrm{p}<0.001$ in all cases). The vertical luminophore profiles assessed by these 2 approaches were thus almost identical (Fig. 1B).

\section{Abra ovata}

The final distribution of luminophores in aquaria containing bivalves showed significant sediment reworking. Conversely, in control aquaria, luminophores remained at the water-sediment interface during the whole experiment. Visual observations carried out throughout the experiment revealed that after their initial burying, bivalves did not change position within the sediment. Initially, the inhalant siphon was erected vertically above the shell and later it began exploring the sediment surface. During this process the inhalant siphon periodically retracted and then re-emerged a few millimetres away, which progressively extended the search area around the first siphonal channel. This behaviour resulted in the formation of a reworked area with a typical inverse conical shape (Fig. 2). The recording of the position of individual bivalves at the end of the experiments confirmed their localisation below the summit of the cones.

The deepest occurring luminophores were located at the summit of the cones. MPD increased significantly with experiment durations (2-way ANOVA, p < 0.001; Fig. 3A). At time 0, the deeper fluorescent particles were, on average, located $1.09 \mathrm{~cm}$ below the surface, as they were buried in the large galleries initially formed by Abra ovata. During the first $6 \mathrm{~h}$, luminophores were transported downwards in the sediment at a mean rate of $0.13 \mathrm{~cm} \mathrm{~h}^{-1}$, and MPDs were similar between all food treatments. After $6 \mathrm{~h}$, MPD increased more slowly (mean rate of $0.02 \mathrm{~cm} \mathrm{~h}^{-1}$ ), and greater differences appeared between treatments. After $48 \mathrm{~h}$, MPDs were between 1.93 and $4.90 \mathrm{~cm}$, with a mean of $3.25 \mathrm{~cm}$ in Treatment $\mathrm{T}$, between 1.56 and $4.25 \mathrm{~cm}$, with a mean of $3.18 \mathrm{~cm}$ in Treatment $\mathrm{B}$, and between 1.42 and $7.21 \mathrm{~cm}$, with a mean of $4.04 \mathrm{~cm}$ in Treatment A. Overall, MPDs seemed greater for Treat- 

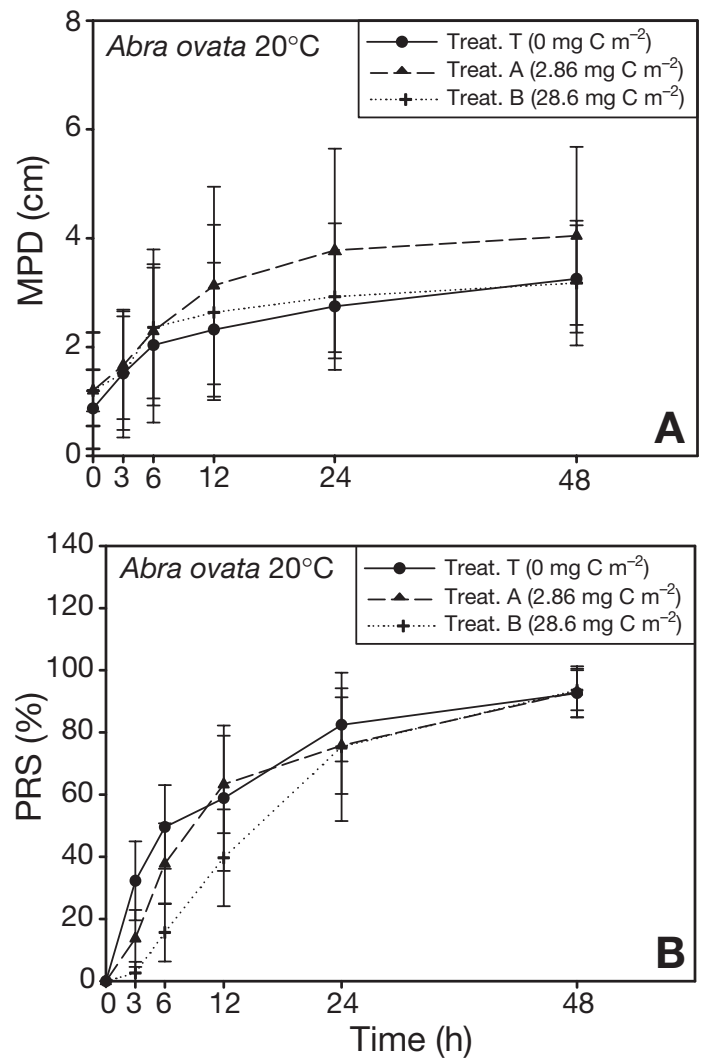

Fig. 3. Abra ovata. Temporal changes in (A) MPD (maximum luminophore penetration depth) and (B) PRS (proportion of reworked sediment surface) for the 3 food treatments. Vertical bars are standard deviations ment A than for Treatments T and B. However, these differences were not statistically significant (2-way ANOVA, $p=0.054$ ) due to the high variability within each treatment.

PRSs increased significantly with experiment durations (2-way ANOVA, p < 0.001) and were significantly affected by food treatments (2-way ANOVA, p $<0.001$; Fig. 3B), with a significant interaction between experiment duration and food treatment $(\mathrm{p}<0.001)$. During the first $24 \mathrm{~h}$, PRSs were higher for Treatments $\mathrm{T}$ and A. After 48 h, PRS averaged $93 \%$ for all 3 food treatments.

Three main types of vertical luminophore profiles were observed (Fig. 4). Type 1 consisted of an exponential decrease of tracer concentration with depth. Type 2 consisted of an exponential decrease with a subsurface secondary peak. Type 3 was characterised by a subsurface peak with surficial layers almost completely devoid of fluorescent particles. Temporal changes in the proportions of these profiles are presented in Table 1. When considering the whole aquarium, luminophore profiles were mostly of Types 1 and 2 during the first $24 \mathrm{~h}$, whereas Type 3 was most frequent after $48 \mathrm{~h}$. The same pattern, with an even higher proportion of profiles of Type 3 after $24 \mathrm{~h}$, was observed when the analysis was restricted to characteristic conical areas (see below).

An example of a vertical luminophore profile together with the corresponding fitting of the biodiffusion model is presented in Fig. 5A. $D_{\mathrm{b}}$ values were first
Type 1

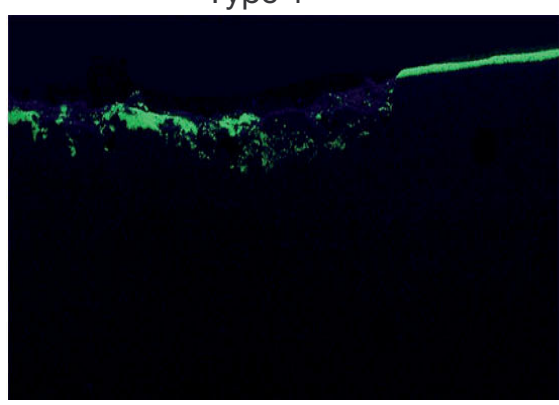

Luminophore pixels

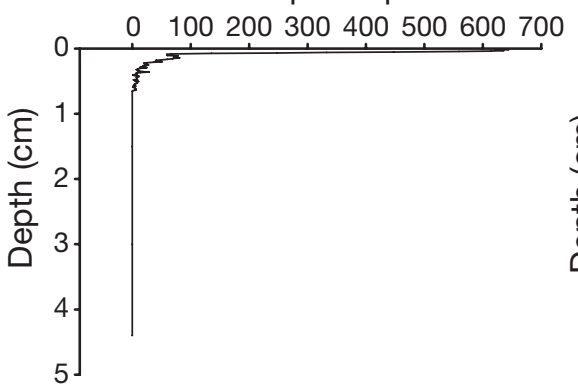

Type 2

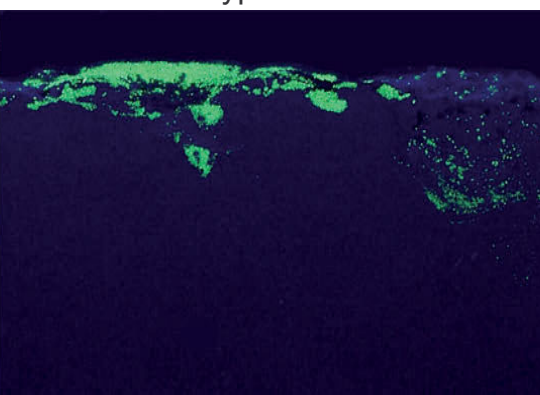

Luminophore pixels

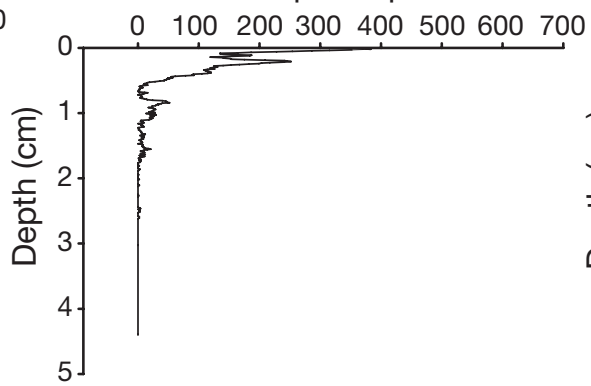

Type 3

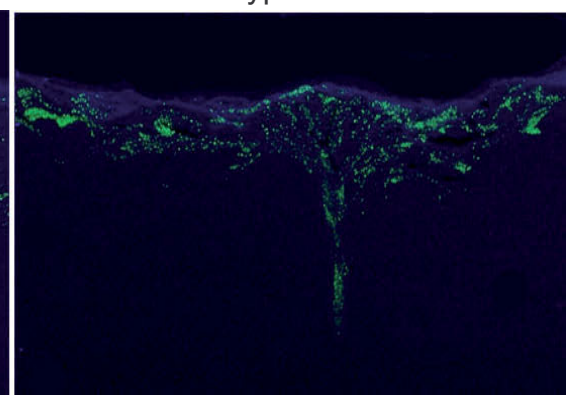

Luminophore pixels

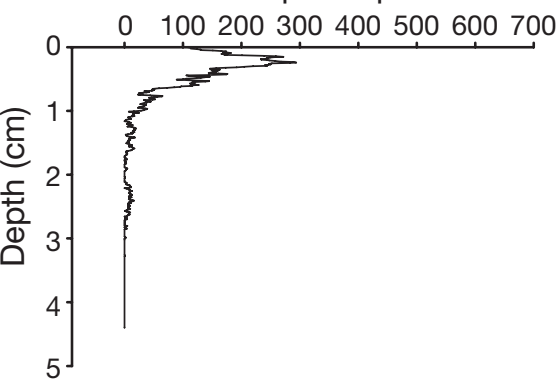

Fig. 4. Abra ovata. Presentation of the 3 main types of luminophore vertical profiles: upper panels are original images; lower panels are the corresponding vertical profiles 
computed by fitting to profiles of whole aquaria. $D_{\mathrm{b}}$ values increased significantly with experiment durations (2-way ANOVA, p < 0.001) and were significantly affected by food treatments as well (2-way ANOVA, $\mathrm{p}<0.001)$, with no significant interaction between these 2 factors ( $p=0.615$; Fig. 6). Temporal changes mostly corresponded to an increase of $D_{\mathrm{b}}$ with experiment durations in Treatment B and to a lesser extent in Treatments A and T. Treatment A resulted in the highest $D_{\mathrm{b}}$ values (LSD-test, $\mathrm{p}<0.05$ ). Corresponding $D_{\mathrm{b}}$ values were between 4.38 and $95.80 \mathrm{~cm}^{2} \mathrm{yr}^{-1}$, with an average of $42.51 \mathrm{~cm}^{2} \mathrm{yr}^{-1}$. Treatment $\mathrm{T}$ resulted in intermediate $D_{\mathrm{b}}$ values (between 2.47 and $41.30 \mathrm{~cm}^{2} \mathrm{yr}^{-1}$, with an average of $22.71 \mathrm{~cm}^{2} \mathrm{yr}^{-1}$ ). Treatment B resulted in the lowest $D_{\mathrm{b}}$ values (LSD-test, $\mathrm{p}<0.05$ ). Corresponding $D_{\mathrm{b}}$ values were between 1.26 and $49.38 \mathrm{~cm}^{2} \mathrm{yr}^{-1}$, with an average of $11.21 \mathrm{~cm}^{2} \mathrm{yr}^{-1}$.

\section{Abra nitida}

Patterns of sediment reworking differed in A. nitida and in A. ovata. As opposed to what was observed for A. ovata, A. nitida sometimes moved within the sediment. Moreover, in A. nitida, the inhalant siphon tend-

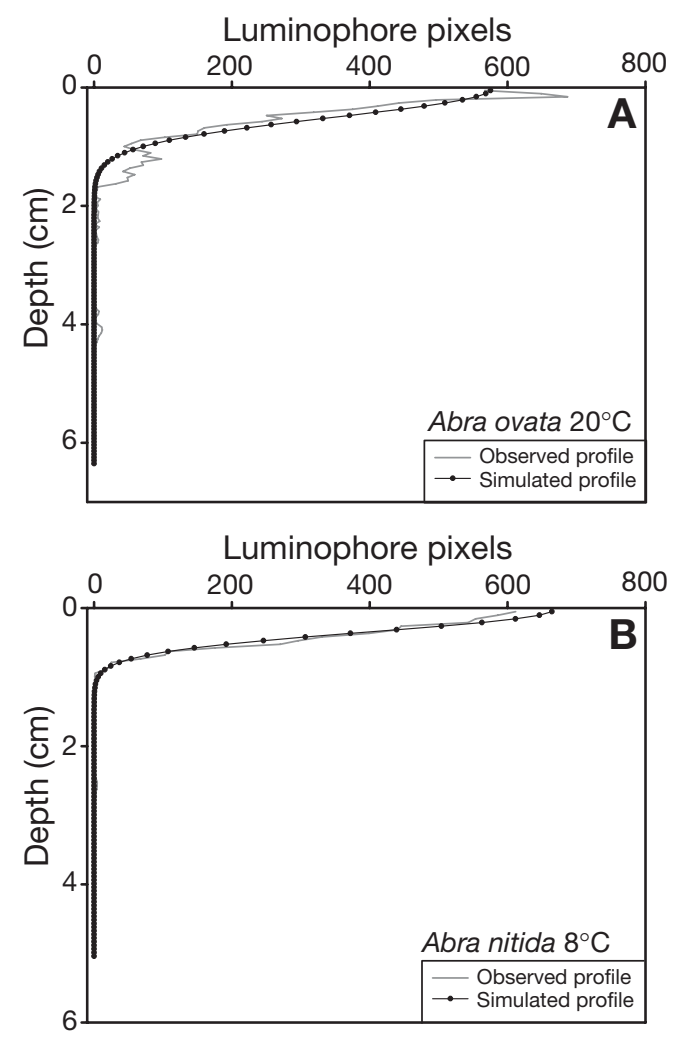

Fig. 5. Abra spp. Examples of the fitting of the biodiffusion model to vertical luminophore profiles: (A) A. ovata $\left(20^{\circ} \mathrm{C}\right)$ and (B) A. nitida $\left(8^{\circ} \mathrm{C}\right)$

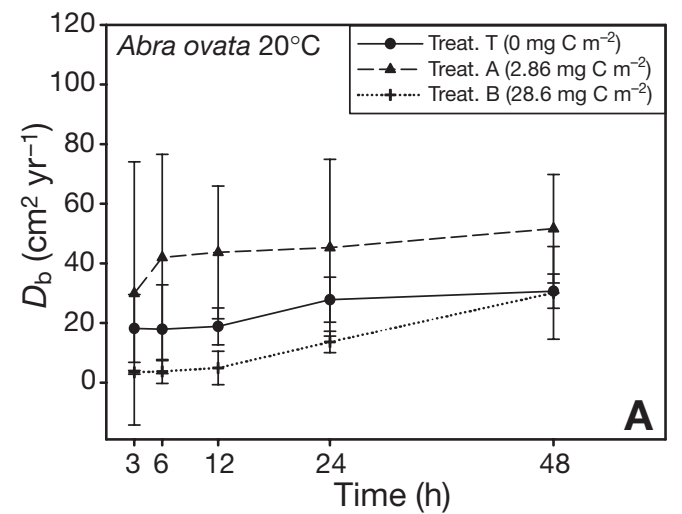

Fig. 6. Abra ovata. Temporal changes in average $D_{\mathrm{b}}$ when computed based on whole aquaria. Vertical bars are standard deviations

ed to 'randomly' prospect the sediment surface, and the sediment area located right above the shell did not constitute a favoured foraging area. This resulted in a reworking of surficial sediment without particular structures, in contrast to those observed for A. ovata (Fig. 7).

MPDs were significantly affected by experiment durations, food treatments and temperature (3-way ANOVAs, $\mathrm{p}<0.001, \mathrm{p}=0.014$ and $\mathrm{p}=0.045$, respectively), with no significant interaction between these 3 factors. MPDs increased with experiment durations (Fig. 8A, D). At time 0, the average MPDs were $0.85 \mathrm{~cm}$. During the first $12 \mathrm{~h}$, luminophores penetrated quickly into the sediment at a mean rate of $0.06 \mathrm{~cm} \mathrm{~h}^{-1}$. After $12 \mathrm{~h}$, MPDs increased much more slowly (mean rate of $0.009 \mathrm{~cm} \mathrm{~h}^{-1}$ ). MPDs were maximal in Treatment B. The highest MPDs were measured in Treatment B (between 0.81 and $3.82 \mathrm{~cm}$, with an average of $2.05 \mathrm{~cm}$ at $8^{\circ} \mathrm{C}$, and between 0.86 and $4.74 \mathrm{~cm}$, with an average of $2.85 \mathrm{~cm}$ at $15^{\circ} \mathrm{C}$ after $48 \mathrm{~h}$ ). MPDs thus tended to be higher at 15 than at $8^{\circ} \mathrm{C}$.

PRSs were also significantly affected by experiment durations, food treatments and temperature (3-way ANOVAs, $\mathrm{p}<0.001, \mathrm{p}<0.001$ and $\mathrm{p}=0.035$, respectively), with significant interaction between experiment durations and food treatments and between food treatments and temperature $(\mathrm{p}<0.001$ in both cases; Fig. 8B, E). PRSs increased with experiment durations; however, this increase occurred much earlier and was steeper in Treatments A and B than in Treatment T. PRSs were higher when food was added (Treatments A and $\mathrm{B})$. At $8^{\circ} \mathrm{C}$ PRSs were higher in Treatment $\mathrm{B}$ than in Treatment A, whereas PRSs associated with these 2 treatments were almost similar at $15^{\circ} \mathrm{C}$. The significant effect of temperature mostly reflected higher values of PRSs in Treatment A at $15^{\circ} \mathrm{C}$.

An example of a luminophore profile for Abra nitida is presented in Fig. 5B. The same 3 types of vertical luminophore profiles were observed as in A. ovata. 
However, their proportions were different (Table 1), as profiles of Types 1 and 2 were always dominant. $D_{\mathrm{b}}$ values were significantly affected by experiment durations and food treatments, but not by temperature (3way ANOVAs, $\mathrm{p}<0.001, \mathrm{p}<0.001$ and $\mathrm{p}=0.975$, respectively), with a significant interaction between experiment durations and food treatments $(p=0.001$; Fig. 8C, F). $D_{\mathrm{b}}$ tended to decrease with experiment duration. $D_{\mathrm{b}}$ values were highest in Treatment B, intermediate in Treatment $\mathrm{A}$ and lowest in Treatment $\mathrm{T}$. The interaction between experiment durations and food treatments mostly reflected the fact that differences in $D_{\mathrm{b}}$ between food treatments decreased with experiment duration. The most important differences between treatments were observed after 3 and $6 \mathrm{~h}$. After $12 \mathrm{~h}$, there was only little difference in $D_{\mathrm{b}}$ among treatments.

\section{Comparison between Abra ovata and A. nitida}

The comparison between $A$. nitida and $A$. ovata was based on the results of experiments performed at 8 and $20^{\circ} \mathrm{C}$, respectively (i.e. at the 2 seawater temperatures during field collection). MPDs were significantly affected by experiment durations, food treatments and species (3-way ANOVAs, p $<0.001, \mathrm{p}=0.037$ and $\mathrm{p}<0.001$, respectively), with a significant interaction between experiment durations and species $(p=0.014)$. MPD increased with experiment duration. MPDs were almost similar for both tested species at the beginning of the experiments and then became higher for $A$. ovata. Despite the lack of significant interaction between food treatments and species ( $\mathrm{p}=0.083)$, MPDs were clearly higher in Treatment $\mathrm{A}$ in $A$. ovata and in Treatment B in A. nitida.

PRSs were significantly affected by experiment durations, food treatments and species (3-way ANOVAs, $\mathrm{p}<0.001$ in all cases), with significant interactions between experiment durations and species and between food treatments and species $(\mathrm{p}<0.001$ and $\mathrm{p}<0.001$, respectively). PRS increased with experiment duration. This increase was much steeper in Abra nitida than in A. ovata, which accounted for the significant interaction between experiment durations and species. As stated above, PRSs in A. nitida were always highest in Treatment $B$, intermediate in Treatment $A$ and lowest in Treatment T. Conversely, PRS in A. ovata tended to be higher in Treatments $\mathrm{T}$ and $\mathrm{A}$ and lower in Treatment B. This discrepancy accounted for the significant interaction between food treatments and species. PRS clearly differed between species. Values first tended to be higher in A. nitida (Food Treatments B and A) and then became higher in A. ovata after $48 \mathrm{~h}$.
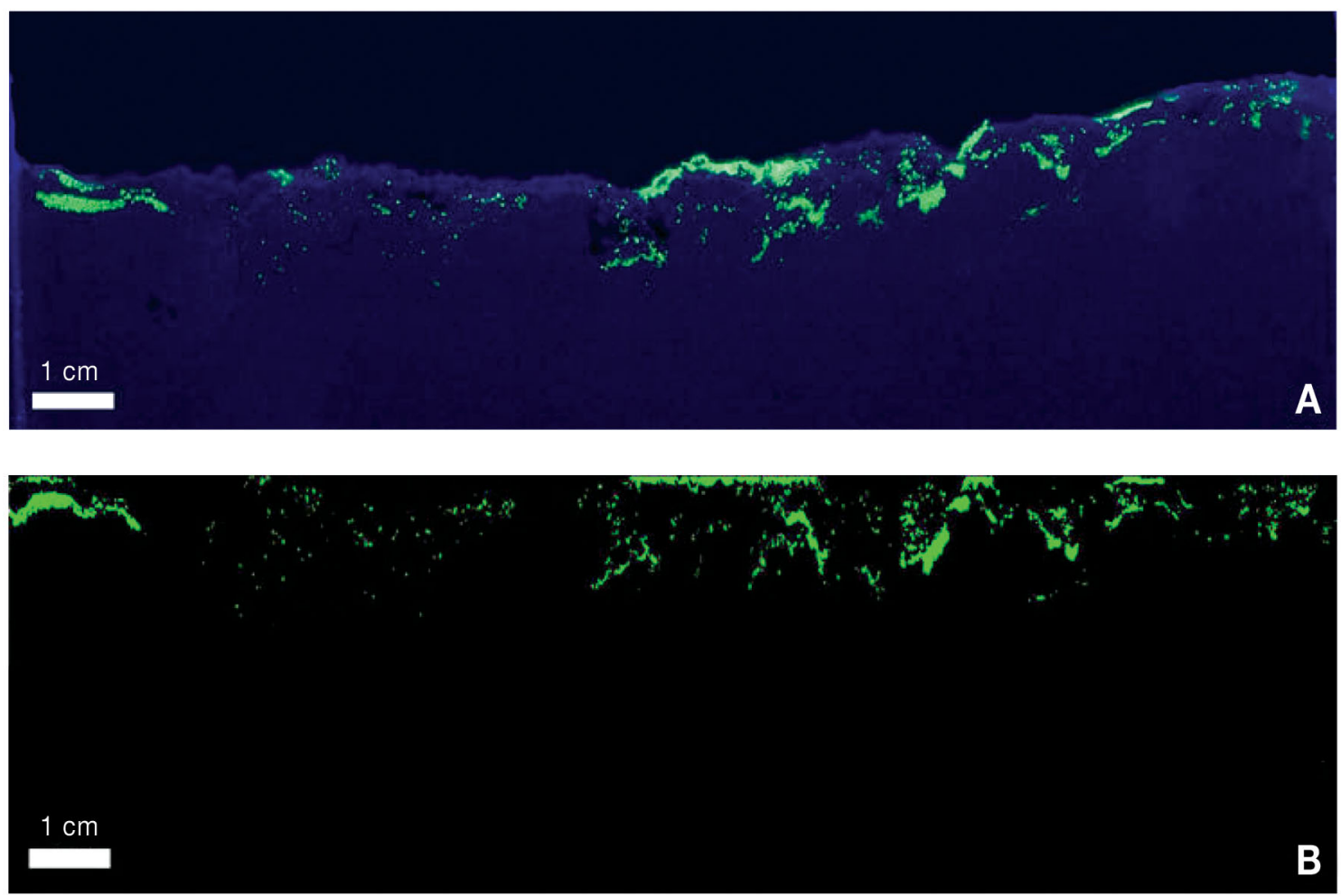

Fig. 7. Abra nitida. (A) Example of an original image with the sediment appearing in dark and luminophores in green. (B) Corresponding thresholded image with a flattened sediment-water interface. Note the lack of inverse conical structures 
$D_{\mathrm{b}}$ significantly differed between experiment durations and food treatments, but not between species (3-way ANOVAs, $\mathrm{p}=$ $0.004, p=0.001$ and $p=0.225$, respectively), with significant interactions between experiment durations and species and between food treatments and species $\left(\mathrm{p}<0.001\right.$ and $\mathrm{p}<0.001$, respectively). $D_{\mathrm{b}}$ in Abra ovata tended to increase with experiment duration, whereas $D_{\mathrm{b}}$ in $A$. nitida clearly decreased with experiment duration. $D_{\mathrm{b}}$ values in $A$. ovata were highest in Treatment $\mathrm{A}$, intermediate in Treatment $\mathrm{T}$ and lowest in Treatment B. Conversely, $D_{\mathrm{b}}$ values in $A$. nitida were highest in Treatment $\mathrm{B}$, intermediate in Treatment $\mathrm{A}$ and lowest in Treatment T. In A. nitida differences in $D_{\mathrm{b}}$ between food treatments decreased with experiment duration. $D_{\mathrm{b}}$ first tended to be higher in A. nitida (especially in Food Treatments B and A) and then became higher in A. ovata after $48 \mathrm{~h}$.

\section{Effect of spatial scale on the computation of $D_{\mathrm{b}}$}

Besides through food treatments and species, $D_{\mathrm{b}}$ values were also significantly affected by spatial scale (3-way ANOVA, $p<0.001$; Fig. 9). There was a significant interaction between spatial scale and experiment (i.e. Abra ovata $20^{\circ} \mathrm{C}$, A. nitida $8^{\circ} \mathrm{C}$ and A. nitida $15^{\circ} \mathrm{C}$ ), but not between spatial scale and food treatment (3-way ANOVAs, $p=0.002$ and $p=0.065$, respectively). Overall, $D_{\mathrm{b}}$ values computed at small spatial scales tended to be higher and also much more variable than those computed at large spatial scales. For the 3 experiments, average values of $D_{\mathrm{b}}$ became closer to the value computed for the whole aquarium for linear sections $>3.750 \mathrm{~cm}$. The interaction between spatial scale and experiments mostly resulted from the occurrence of a peak in $D_{\mathrm{b}}$ at intermediate spatial scale (i.e. $0.037 \mathrm{~cm}$ ) during the $A$. nitida experiment carried out at $8^{\circ} \mathrm{C}$. The results of this experiment also suggest that the effect of spatial scale on $D_{\mathrm{b}}$ was higher for Treatments A and B (i.e. when $D_{\mathrm{b}}$ values were higher).

In Abra ovata, $D_{\mathrm{b}}$ values computed for characteristic conical biogenic structures were significantly higher than those com-

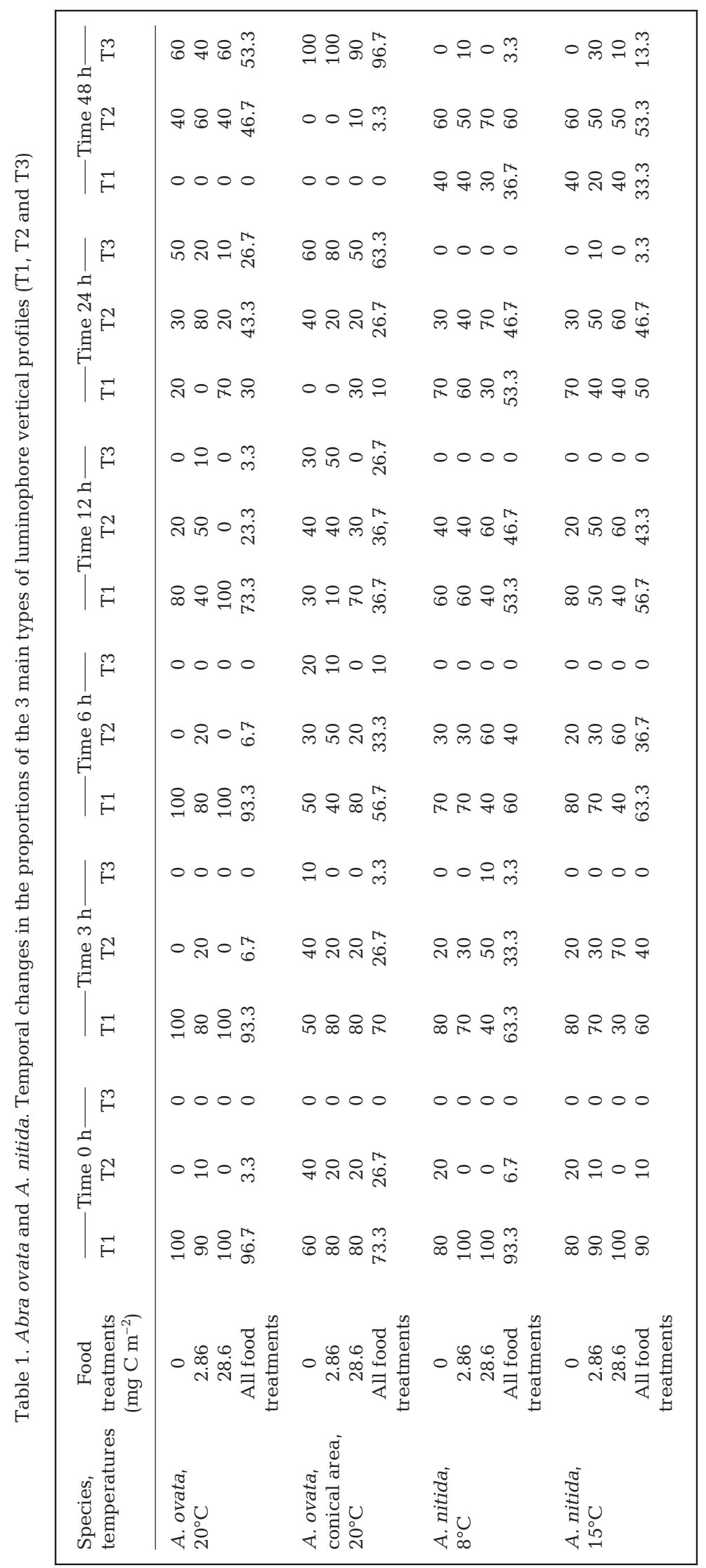



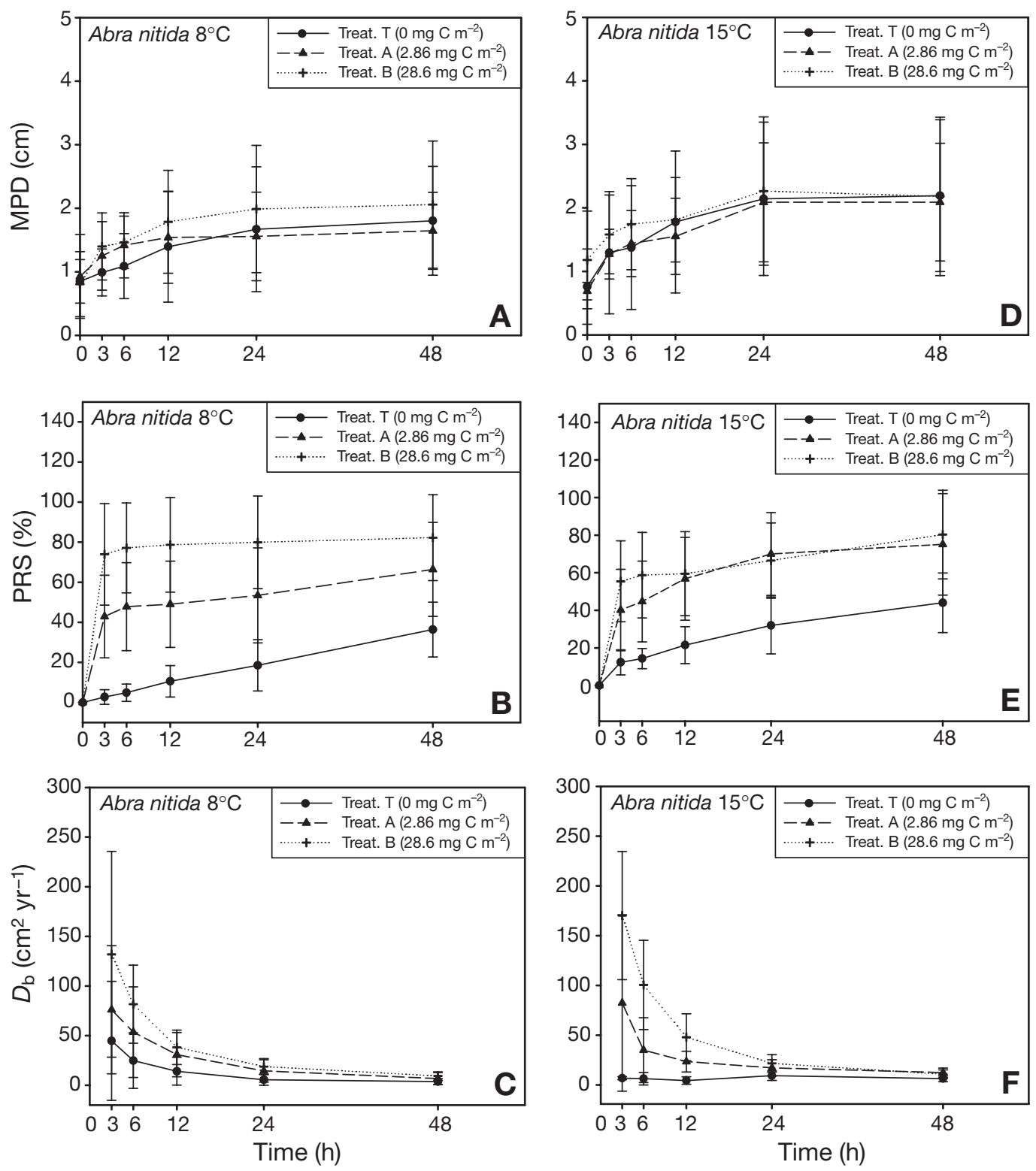

Fig. 8. Abra nitida. Temporal changes in average (A, D) MPDs, $(\mathrm{B}, \mathrm{E})$ PRSs and $(\mathrm{C}, \mathrm{F}) D_{\mathrm{b}}$ recorded during the (A to C) 8 and (D to F) $15^{\circ} \mathrm{C}$ experiments. Vertical bars are standard deviations

puted based on the whole aquarium (3-way ANOVA, $\mathrm{p}<0.001$; Fig. 10). Here again, average $D_{\mathrm{b}}$ increased significantly with experiment duration and significantly differed between treatments (3-way ANOVAs, $\mathrm{p}<0.001$ in both cases). There was significant interaction between the surface used for the computation of $D_{\mathrm{b}}$ and experiment duration, but not with food treatments (3-way ANOVAs, $p<0.005$ and $p=0.933$ ). The most important differences between treatments were recorded between 6 and $24 \mathrm{~h}$, when Treatment A resulted in higher $D_{\mathrm{b}}$ than Treatments $\mathrm{T}$ and B. After $48 \mathrm{~h}, D_{\mathrm{b}}$ values were similar in all 3 treatments (mean $D_{\mathrm{b}}$ of $97.07 \mathrm{~cm}^{2} \mathrm{yr}^{-1}$ for Treatment $\mathrm{T}, 90.93 \mathrm{~cm}^{2} \mathrm{yr}^{-1}$ for Treatment A and $98.32 \mathrm{~cm}^{2} \mathrm{yr}^{-1}$ for Treatment B).
The size of the vertical grid significantly affected $D_{\mathrm{b}}$ (3-way ANOVA, $\mathrm{p}<0.001$; Fig. 11), with a significant interaction between grid size and experiments, but not between grid size and food treatments (3-way ANOVAs, $p=0.003$ and $p=0.963$, respectively). The effect of grid size was much less pronounced in Abra ovata than in A. nitida. In A. ovata, $D_{\mathrm{b}}$ increased only slightly with vertical grid size (e.g. from 30.68 to $41.77 \mathrm{~cm}^{2} \mathrm{yr}^{-1}$ for grid sizes 0.052 and $0.998 \mathrm{~cm}$, respectively, during Treatment $T_{;}$Fig. 11). This increase was much more pronounced in $A$. nitida, especially for grid sizes $>0.247 \mathrm{~cm}$ (e.g. from 3.41 to 3.97 and $18.77 \mathrm{~cm}^{2} \mathrm{yr}^{-1}$ for grid sizes of $0.052,0.247$ and $0.998 \mathrm{~cm}$, respectively, during Treatment $\mathrm{T}$ at $8^{\circ} \mathrm{C}$ ). 


\section{DISCUSSION}

\section{Description of sediment reworking in Abra ovata and A. nitida}

In control aquaria without bivalves, luminophores remained at the sediment surface during the whole duration of the experiments and there was no temporal change in luminophore vertical profiles. Thus, sediment reworking by small infaunal organisms $(<1 \mathrm{~mm})$ and/or physical disturbance (e.g. caused by running
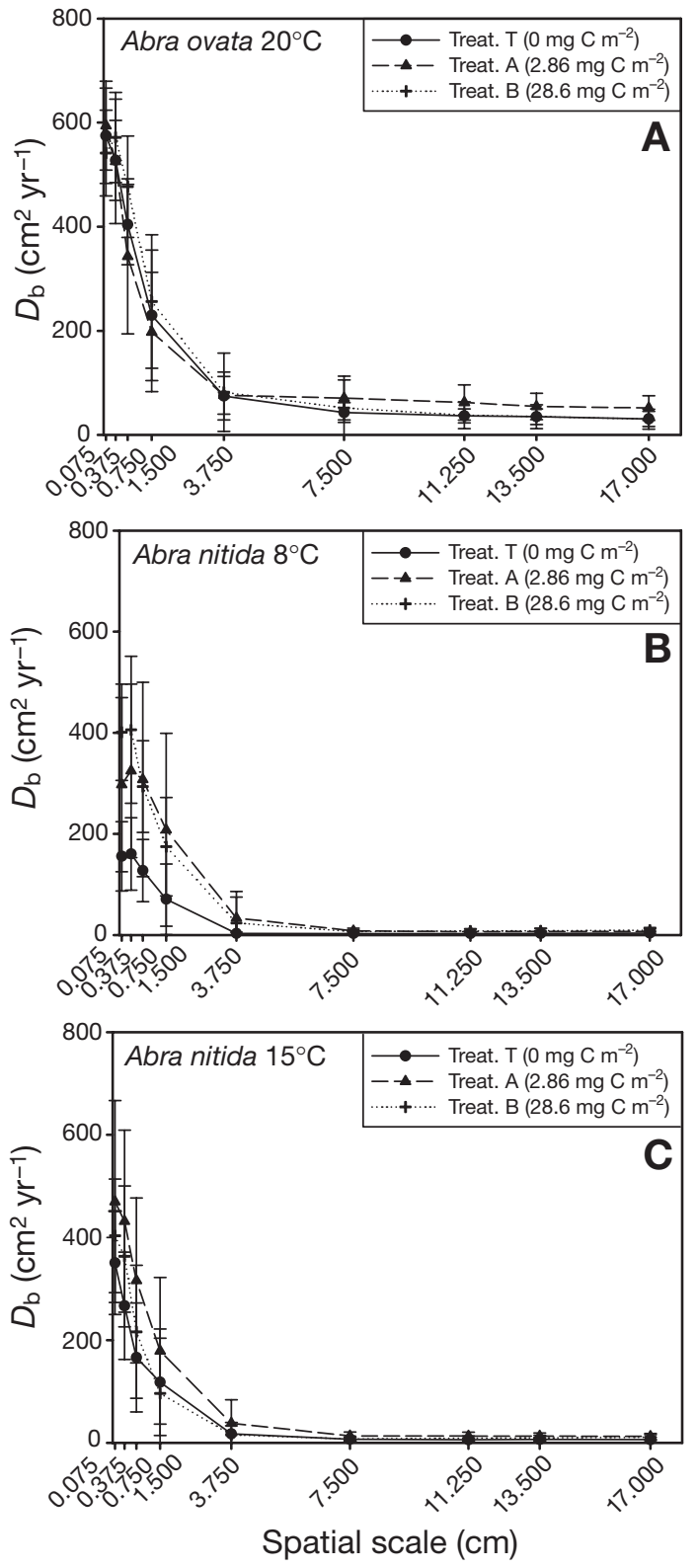

Fig. 9. Abra spp. Changes in average $D_{\mathrm{b}}$ computed at $48 \mathrm{~h}$ for increasing horizontal spatial scales: (A) A. ovata $\left(20^{\circ} \mathrm{C}\right)$, (B) A. nitida $\left(8^{\circ} \mathrm{C}\right)$ and $(\mathrm{C}) A$. nitida $\left(15^{\circ} \mathrm{C}\right)$. Vertical bars are standard deviations

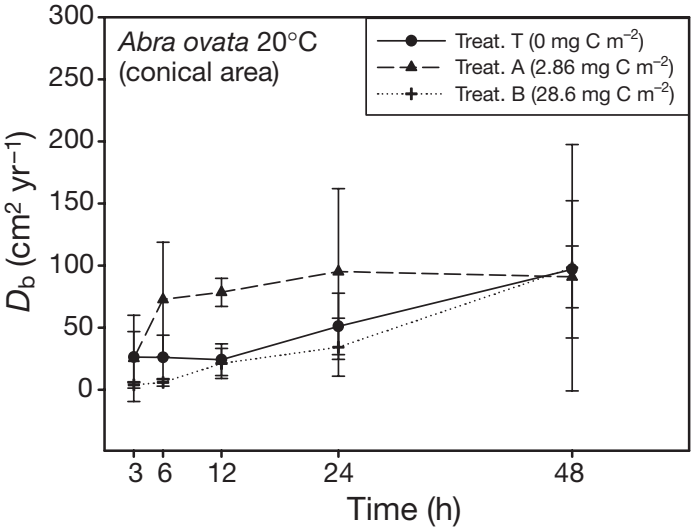

Fig. 10. Abra ovata. Temporal changes in average $D_{\mathrm{b}}$ when computed based on inverse conical areas (see 'Results'). Vertical bars are standard deviations

seawater arrival) were negligible, and the observed patterns of sediment reworking clearly resulted from the activity of the 2 tested bivalves.

Abra ovata and A. nitida clearly exhibited 2 distinct patterns of sediment reworking corresponding to their feeding behaviour and, more specifically, to their motility and the functioning of their inhalant siphons. In A. ovata, distinct biogenic structures associated with sediment reworking by individual bivalves were observed at the end of all experiments. These structures consisted of inverse cones enriched in luminophores relative to the surrounding sediment. They coincided with the network of siphonal channels created by A. ovata from the subsurface chamber where it is located in the sediment. The tip of the cone was located right above this chamber, and the base of the cone corresponded to a section of the area explored by the inhalant siphon. We observed that $A$. ovata explored the sediment by: (1) extending the tip of its inhalant siphon from the aperture of a siphonal channel and (2) the creation of new siphonal channels. In this species, the first siphonal channel was always located almost vertically above the subsurface chamber. Two consecutive channels were always very close to one another, and the bivalves increased the surface of the explored area by progressively increasing the angle of their siphonal channels from the vertical. Due to the stationary position of A. ovata in the sediment this resulted in a network of galleries with a typical inverse conical shape. According to our observations, the downward transport of luminophores within this network resulted from small-scale transfer toward depth during each retraction of the siphon. A network of galleries with a similar inverse conical shape was described earlier for the network of siphonal channels in A. nitida (Wikander 1980). However, we did not observe any such structures during our experiments with A. nitida. Grémare et al. (2004) found that A. nitida 

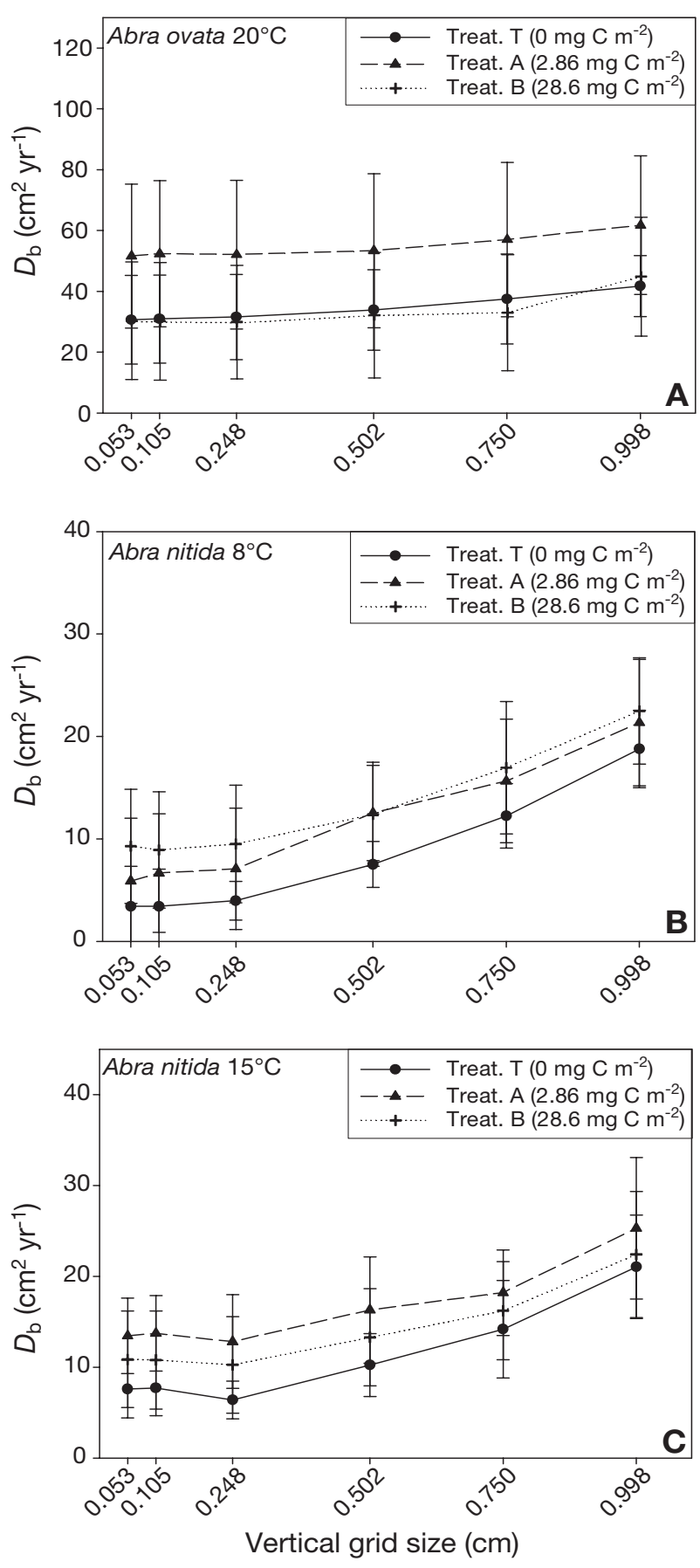

Fig. 11. Abra spp. Effect of vertical grid size on the computation of $D_{\mathrm{b}}$ : (A) A. ovata $\left(20^{\circ} \mathrm{C}\right)$, (B) A. nitida $\left(8^{\circ} \mathrm{C}\right)$ and $(\mathrm{C})$ A. nitida $\left(15^{\circ} \mathrm{C}\right)$. Vertical bars are standard deviations

could move quickly in the sediment in response to food addition. This was probably causing the sediment reworking patterns of $A$. nitida. The similarity of those patterns between the 3 food treatments constituted indirect evidence that $A$. nitida was moving in the sediment even when food availability was low.
During the first $24 \mathrm{~h}$ of the experiments, luminophore concentration decreased exponentially (Type 1) with depth in most cases for both Abra ovata and A. nitida. Later, most of the luminophore profiles exhibited a subsurface secondary peak in luminophore concentration (Type 2). In A. ovata only, subsurface primary peaks (Type 3) were often observed after $48 \mathrm{~h}$. Vertical profiles are often used as indicators of sediment reworking types. They classically allow for the distinction between biodiffusion and non-local transport. Exponential profiles are associated with biodiffusion (Guinasso \& Schink 1975, Cochran 1985, François et al. 1997, 2001), whereas profiles featuring a subsurface peak are often considered as indicative of non-local transport (Boudreau 1986, Meysman et al. 2003, Mugnai et al. 2003). Observations carried out during the beginning of our experiments strongly suggested that both $A$. ovata and $A$. nitida were biodiffusers (François et al. 1997). However, vertical luminophore profiles showing subsurface peaks were dominant in both species after $48 \mathrm{~h}$. This was probably not indicative of non-local transport, since we did not observe either luminophore transport over long distances or luminophore patches indicative of non-local transport. Instead, our observations showed that subsurface peaks resulted from both: (1) the initial penetration of luminophores in the galleries formed by bivalves when burying and (2) the depletion of luminophores at the sediment surface due to feeding by the bivalves. Subsurface peaks, therefore, did not result from the transfer of luminophores to depth, but rather from differential intake at the sediment surface and at the depth of the subsurface peaks, where luminophores were initially introduced but later slowly reworked. A similar process has already been described for a natural Mediterranean species assemblage (Gérino et al. 1994). Based on our results, A. ovata and $A$. nitida clearly appeared as biodiffusers.

There were also considerable differences between Abra ovata and A. nitida in PRS and MPD. After $48 \mathrm{~h}$ with no food addition, $A$. nitida reworked on average $40 \%$ of the total surface of the aquarium versus $93 \%$ for A. ovata. As observed by Grémare et al. (2004), the extension of the inhalant siphon in A. nitida is limited, whereas $A$. ovata can extend its inhalant siphon over larger distances (typically a few centimetres) and is thus capable of exploring larger areas of the sediment without moving its shell. In the absence of food addition, this behaviour resulted in larger reworked areas than in A. nitida, despite A. ovata being stationary. It should, however, be pointed out that the surface affected by sediment reworking in A. ovata quickly decreased with depth, whereas it was constant over the whole reworked sediment layer for A. nitida. A. ovata also tended to rework a thicker sediment layer $(3 \mathrm{~cm}$ on average) than $A$. nitida (1.5 $\mathrm{cm}$ on average). Differ- 
ences in sediment reworking between the 2 species may be a consequence of specific adaptations to avoid and reduce predation and to handle hydrodynamic conditions prevailing in their respective habitats. Grémare et al. (2004) suggested that the low extension of the inhalant siphon in $A$. nitida could be an adaptation to avoid siphon nipping by juvenile benthic fishes. Along the same line, deeper burying in A. ovata may constitute an adaptation to avoid resuspension by strong currents and waves (Millet \& Guelorget 1994), which may occur in shallow Mediterranean lagoons during winter storms.

\section{Quantification of sediment reworking: effects of food availability}

Quantification of sediment reworking based on optic measurements of luminophores mixing along the thin planes adjacent to the glass of an experimental aquarium or a sediment profiler has already been used both during in situ (Solan et al. 2004b) and laboratory experiments (Gilbert et al. 2003). One of the key assumptions of this approach is that the sediment mixing observed on the photographs is representative of that taking place in the entire sediment column. To our knowledge, this hypothesis has never been tested. Our results showed that there was a strong correlation between the concentrations of luminophores derived from: (1) the analysis of the photographs of the walls of 5 experimental aquaria and (2) the direct counting of sediment slices of the whole corresponding aquarium. As a consequence, the vertical profiles obtained by these 2 approaches were almost identical, which clearly supports the experimental approach used during the present study.

Bivalve densities used during our experiments were compatible with field abundances reported for the
2 tested species (Guelorget \& Mayere 1981, Josefson 1982). Our results clearly showed that sediment reworking by the 2 tested bivalves quickly led to a major reduction of luminophore concentrations at the water-sediment interface, which may have biased the computation of $D_{\mathrm{b}}$ should experiments have been prolonged. More generally, all experiments carried out under non-steady conditions are limited by the tracer availability at the water-sediment interface (Gérino et al. 1994). Moreover, it should be stressed that such a depletion of luminophores may well occur faster in preferentially reworked area and may thus not be apparent if vertical luminophore profiles are computed for whole experimental aquaria. To overcome this bias, our experiments were restricted to $48 \mathrm{~h}$, which is very short term compared to radioisotope measurements (Sharma et al. 1987, Soetaert et al. 1996, Wheatcroft \& Martin 1996, Alperin et al. 2002, Green et al. 2002) or even to most experiments involving luminophores (Table 2).

It is essential that such short-term experiments are carried out on well-acclimated animals. During the present study, we introduced the bivalves into the experimental aquaria $24 \mathrm{~h}$ before the beginning of the experiments. Grémare et al. (2004) used a similar procedure to study the feeding activity of Abra ovata and A. nitida and concluded that this acclimation period resulted in a constancy of feeding behaviours during short-term experiments. Due to the strong correlation between biological activity and sediment reworking, we are thus confident in stating that the acclimation period used during the present study was sufficient to insure adequate quantification of $D_{\mathrm{b}}$.

The validity of our experimental approach is further supported by a comparison between the $D_{\mathrm{b}}$ values recorded during the present study and literature data. Without food addition, our $D_{\mathrm{b}}$ values averaged 30.7 and $3.7 \mathrm{~cm}^{2} \mathrm{yr}^{-1}$, based on $48 \mathrm{~h}$ studies for Abra ovata

Table 2. Compilation of literature values of $D_{\mathrm{b}}$, computed based on luminophore experiments and the biodiffusive model

\begin{tabular}{|llrcrll|}
\hline $\begin{array}{l}\text { Geographical } \\
\text { area }\end{array}$ & Species & $\begin{array}{c}D_{\mathrm{b}} \\
\left(\mathrm{cm}^{2} \mathrm{yr}^{-1}\right)\end{array}$ & $\begin{array}{c}\text { Experiment } \\
\text { duration }(\mathrm{h})\end{array}$ & $\begin{array}{c}\text { Temperature } \\
\left({ }^{\circ} \mathrm{C}\right)\end{array}$ & $\begin{array}{c}\text { Density } \\
\left(\mathrm{ind}^{-2}\right)\end{array}$ & Source \\
\hline Gulf of Fos & Field community & 219.80 & 528 & & & Gérino (1990) \\
Gullmarsfjord & Field community & 14.00 & 216 & & & Gilbert et al. (2003) \\
Gullmarsfjord & Field community & 126.00 & 16 & & & Solan et al. (2004b) \\
Laboratory & Ruditapes decussatus & 5.11 & 168 & 15 & 724 & François et al. (1998) \\
Laboratory & Venus aurea & 2.78 & 168 & 15 & 724 & François et al. (1998) \\
Laboratory & Nereis diversicolor & 3.05 & 360 & 16 & 800 & François et al. (2002) \\
Laboratory & Nereis diversicolor & 5.50 & 720 & 16 & 800 & François et al. (2002) \\
Laboratory & Cardium edule & 0.91 & 480 & 14 & 250 & Mermillod-Blondin et al. (2005) \\
Laboratory & Corophium volutator & 1.82 & 480 & 14 & 5100 & Mermillod-Blondin et al. (2005) \\
Laboratory & Abra ovata & $14.56-69.73$ & 48 & 20 & 1470 & Present study \\
Laboratory & Abra nitida & $0.17-15.70$ & 48 & 8 & 1470 & Present study \\
Laboratory & Abra nitida & $2.47-16.14$ & 48 & 15 & 1470 & Present study \\
\hline
\end{tabular}


and A. nitida, respectively. These values can be compared with literature data based on luminophore experiments and biodiffusive models (Table 2), even though this comparison is complicated by strong heterogeneity in experimental conditions (e.g. individual species vs. species assemblages or whole communities, field vs. laboratory measurements, abundance of macrofauna per unit surface area). Nevertheless, the values recorded during the present study are of the same order of magnitude as literature data. Our $D_{\mathrm{b}}$ values are slightly lower than community estimates carried out in the Gulf of Fos (Gérino 1990) and in the Gullmarsford (Solan et al. 2004b). Conversely our estimates of $D_{\mathrm{b}}$ in $A$. ovata are higher than those reported for other individual species, such as Cardium edule, Corophium volutator, Venus aurea, Ruditapes decussatus and Nereis diversicolor (François et al. 1998, 2002, Mermillod-Blondin et al. 2005). Even if caution should be taken in comparing $D_{\mathrm{b}}$ derived from the measurements of different tracers, it should be pointed out that the range of $D_{\mathrm{b}}$ recorded during the present study (i.e. between 0.2 and $252.3 \mathrm{~cm}^{2} \mathrm{yr}^{-1}$ ) is in good agreement with the overall range of 1 to $400 \mathrm{~cm}^{2} \mathrm{yr}^{-1}$ reported for coastal sediments, mostly based on radioisotope measurements (Tromp et al. 1995). Moreover, the average values recorded during the present study are also close to those recorded by Lecroart et al. (2005) and Schmidt et al. (in press) in the Thau Lagoon (NW Mediterranean), based on both ${ }^{234} \mathrm{Th}$ and ${ }^{7} \mathrm{Be}$ measurements (i.e. up to 10 and $30 \mathrm{~cm}^{2} \mathrm{yr}^{-1}$ depending on the vertical flux of particulate organic matter caused by cultivated bivalves). Mermillod-Blondin et al. (2005) recently underlined the difficulty in comparing the results of sediment reworking experiments dealing with single species and those dealing with assemblages of species. One difficulty is clearly associated with the occurrence of interactions between species, and another one with the way of controlling biomass during comparative experiments. One possibility consists of comparing observed and expected (i.e. computed based on the sum of all the individual sediment reworking rates of the species present in the assemblage) reworking rates. The difference between observed and expected reworking rates is usually negative, pinpointing the occurrence of negative interactions between species (Mermillod-Blondin et al. 2005). Even if caution should clearly be taken in applying the same approach to $D_{\mathrm{b}}$ values recorded in A. ovata and those measured by Lecroart et al. (2005) and Schmidt et al. (in press) in the Thau Lagoon, our results nevertheless suggest that $A$. ovata is a major contributor to sediment reworking in Mediterranean lagoons.

$D_{\mathrm{b}}$ values were significantly affected by food treatment, both in Abra ovata and A. nitida. However, there were clear differences in the functional responses of the 2 tested species. For $A$. ovata, $D_{\mathrm{b}}$ values were highest at intermediate food concentrations and greatly reduced at high food concentrations. Conversely, for A. nitida, $D_{\mathrm{b}}$ increased with food concentration. This pattern is fully coherent with the functional responses exhibited by the same 2 species in terms of feeding activity (Grémare et al. 2004). This further confirms that sediment reworking is mostly caused by feeding activity in the 2 tested bivalves. Moreover, difference in functional response underlines the necessity of running comparative experiments at different food levels for the study of sediment reworking (Grémare et al. 2004). Schmidt et al. (in press) carried out a seasonal survey in the Thau Lagoon based on field measurements of ${ }^{7} \mathrm{Be}$ and ${ }^{234} \mathrm{Th}$ profiles. These authors compared 2 sites, the first one located in the middle of the lagoon and the second one close to aquaculture tables (and thus subject to much higher inputs of organic matter). They consistently reported higher $D_{\mathrm{b}}$ under the aquaculture tables. Unfortunately, no data on the composition of macrofauna are provided, and it is thus impossible to assess the effect of differences in macrofauna on sediment reworking rates. Nevertheless, our data suggest that such differences in $D_{\mathrm{b}}$ may partly result from the functional response of individuals belonging to the same species, but subjected to different levels of organic inputs. More generally, Tromp et al. (1995) reported a positive correlation between $D_{\mathrm{b}}$ and sedimentation rate. This relationship was interpreted to result from the positive correlation between sedimentation rates and vertical fluxes of organic matter to the water-sediment interface, which themselves correlate positively with benthic standing crops. This relationship is clearly associated with large spatio-temporal scales, and our results show that $D_{\mathrm{b}}$ values can also vary over a short temporal scale in response to sedimentation rates.

Sediment reworking can be assessed based on a large variety of tracers, including luminophores, chlorophyll $a$ and radioisotopes such as ${ }^{234} \mathrm{Th}$ and ${ }^{7} \mathrm{Be}$. These tracers integrate sediment reworking on different time scales (Goldberg \& Koide 1962, Gérino et al. 1998, Fuller et al. 1999, Thomson et al. 2000, Lecroart et al. 2005). Due to technical constraints, field measurements of sediment reworking are most often based on the assessment of radioisotope profiles (Rice 1986, Sharma et al. 1987, Wheatcroft \& Martin 1996, Soetaert et al. 1996, Alperin et al. 2002, Green et al. 2002, Kniskern \& Kuehl 2003, Widdows et al. 2004, but Solan et al. 2004b). One of the important assumptions of the models used to derive $D_{\mathrm{b}}$ values from those profiles is the constancy of sediment reworking rates during the period of time integrated by isotope profiles. Our results show that sediment reworking is a process that 
occurs over a short-time scale and can be affected by short-term biological events such as the sedimentation of a phytoplanktonic bloom. In the Skagerrak, for example, pelagic primary production and associated sedimentation show a sharp peak during spring (Lindahl 1988, Belgrano et al. 1999). Such events are typically restricted in time and correspond to a temporal scale shorter than those associated with the measurements of radioisotope profiles. In this sense, our results suggest that field measurements of $D_{\mathrm{b}}$ based on radioisotopes may underestimate maximal sediment reworking rates associated with the sedimentation of phytoplanktonic blooms. Moreover, radioisotopes used to assess sediment reworking generally show a strong affinity for particles. Their flux to the water-sediment interface is thus likely to correlate positively with the vertical flux of organic matter sedimenting to the water-sediment interface. As recently pointed out by Lecroart et al. (in press) this violates the assumption of steady inputs of radioisotopes to the water-sediment interface and may result in an even higher underestimation of computed $D_{\mathrm{b}}$ values during strong sedimentation events. In this context, the use of luminophores as tracers of sediment reworking appears especially suitable to measure and to detect changes in $D_{\mathrm{b}}$ over short time scales since: (1) their input to the watersediment interface is fully controlled and (2) their measured vertical profiles are only dependent on these controlled inputs.

\section{Effects of spatial and temporal scales}

One of the main advantages of the experimental approach used during the present study relative to classical luminophore experiments is that it allows assessment of sediment reworking at spatial scales smaller than the whole studied aquarium. Both in Abra ovata and $A$. nitida, $D_{\mathrm{b}}$ tended to decrease with spatial scales up to $3.75 \mathrm{~cm}$. Part of the relationship between spatial scale and $D_{\mathrm{b}}$ in $A$. ovata clearly resulted from the existence of biogenic structures, which were typically between 3 and $4 \mathrm{~cm}$ wide. $D_{\mathrm{b}}$ values computed for these structures were indeed about twice as high as those computed for the whole aquarium. In A. ovata, the magnitude of the changes in $D_{\mathrm{b}}$ in relation to spatial scale was, however, much larger than a factor of 2 . Moreover, the relationship between $D_{\mathrm{b}}$ and horizontal scale was very similar in $A$. nitida, where biogenic conical structures were absent. One of the main differences between the 2 species was the average PRS after $48 \mathrm{~h}$. In A. ovata, the average PRS was close to $100 \%$ after $48 \mathrm{~h}$ for all treatments, whereas it was between 30 and $80 \%$ in A. nitida. The relationship between horizontal scale and $D_{\mathrm{b}}$ thus probably partly resulted from the heterogeneity between reworked and nonreworked areas in A. nitida and from the heterogeneity associated with biogenic structure within a reworked area in A. ovata. In any case, our results clearly underline the necessity to take into account the appropriate spatial scale to precisely assess individual sediment reworking rates. The relationship between spatial scale and sediment reworking is clearly dependent on the studied animal (or community). It is thus impossible to extrapolate the results of the present study to other experimental models. As far as A. ovata and A. nitida are concerned, our results nevertheless suggest that the sizes of cores (i.e. typically between 50 and $70 \mathrm{~cm}^{2}$ ) used during classical luminophore experiments are suitable to infer sound values of $D_{\mathrm{b}}$.

Our results clearly show the significant effect of vertical grid size on the computation of $D_{\mathrm{b}}$ in Abra nitida, but not in A. ovata. These results are fully consistent with the fact that, in order to allow for sound assessment of sediment reworking, vertical grid size has to be: (1) larger than microscopic sediment variations and (2) smaller than the scale of gradient concentrations (Boudreau 1986). The luminophores used during the present study were between 100 and $160 \mu \mathrm{m}$ in size, and we tested grid sizes between 520 and $9970 \mu \mathrm{m}$. All tested grid sizes were thus clearly larger than microscopic sediment variations. Our results showed that MPDs were higher in A. ovata than in A. nitida. Since the scales associated with gradient concentrations correlate positively with MPD (Boudreau 1986), differences in the effect of vertical grid size on $D_{\mathrm{b}}$ in A. ovata and in A. nitida thus probably corresponded to differences in the scales associated with gradient concentrations in these 2 species. $D_{\mathrm{b}}$ in $A$. nitida started to increase at a vertical grid size as small as $0.5 \mathrm{~cm}$, which is smaller than the minimal thickness of sediment layers sliced during classical luminophore experiments (Gérino et al. 1994, François et al. 1998, 2002, Mugnai et al. 2004, Ouellette et al. 2004, Mermillod-Blondin et al. 2005). Thus, such classical experiments would not be adequate to quantify sediment reworking in A. niti$d a$ unless a technical procedure is found to cut thinner sediment layers. The shape of vertical concentration profiles also constitutes an indicator of sediment reworking types, and the occurrence of a secondary subsurface peak, for example, is generally considered indicative of non-local transport (Boudreau 1986, Meysman et al. 2003, Mugnai et al. 2003). Our results showed that the perception of true profiles is strongly affected by vertical grid size (Fig. 12). More specifically, the subsurface peaks, which were apparent for small grid sizes, tended to disappear for larger grid sizes (Fig.12), and the 'observed' decrease in luminophore concentrations with depth became better fitted using a biodiffusive model. Meysman et al. 

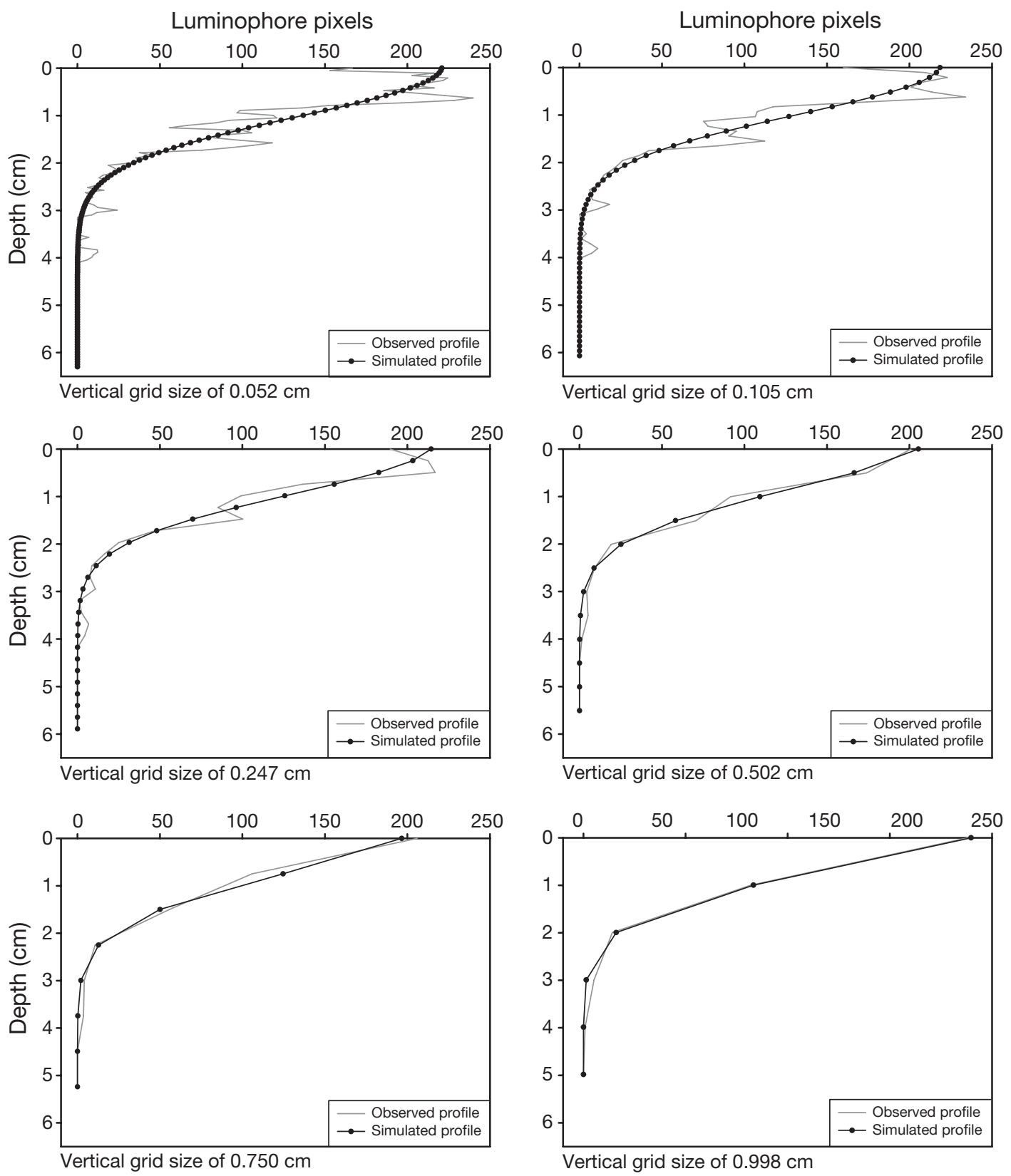

Fig. 12. Example of the effects of vertical grid size on the fitting of the biodiffusive model to vertical luminophore profiles. Data correspond to a Treatment $\mathrm{T}\left(0 \mathrm{mg} \mathrm{C} \mathrm{m}{ }^{-2}\right)$ aquarium with Abra ovata $\left(20^{\circ} \mathrm{C}, 48 \mathrm{~h}\right.$ of experiment)

(2003) recently pointed out the so-called 'biodiffusion paradox', since biodiffusion has proven to constitute an empirical model of reference for sediment reworking even though some of its theoretical requirements (especially the length criterion) are rarely met. The most often invoked explanation for this paradox is that the occurrence of several sediment reworking types within the same community, in the long run (i.e. the integration period of radioisotopes), results in exponential vertical profiles. At the single species level, and over a much shorter time scale, our results suggest that part of the paradox could also result from the low resolution of vertical profiles, which are used to fit sediment reworking models and to infer sediment reworking rates. Such low resolution indeed results in underestimation of subsurface peaks and thus enhances the fitting of biodiffusion models. This hypothesis can be tested by comparing the fittings of both biodiffusive and non-local transport models over a large range of vertical grid sizes. It is suspected that there will be no major differences between models over the whole range of vertical grid sizes in A. ovata 
and $A$. nitida, because these 2 species are both biodiffusers (see above). However, it would be interesting to further test this hypothesis on a data set acquired with the experimental approach used during the present study, but on an animal belonging to another functional group. Overall, our results clearly underline the necessity of adapting vertical grid size to the studied animals or community when assessing sediment reworking rates. Here again, our experimental approach allows a posteriori and highly flexible determination of this grid size.

Another advantage of the experimental approach used during the present study relative to classical luminophore experiments is that it allows assessment of the kinetics of sediment reworking. As mentioned above, our experiments were clearly short term, and care should be taken in interpreting temporal changes. The temporal trends recorded during the present study were in good agreement with previous observations regarding the interaction between feeding activity, feeding intensity and time devoted to feeding in the 2 studied species (Grémare et al. 2004). We thus believe that the temporal trends were real and are worth being discussed. Temporal changes in $D_{\mathrm{b}}$ differed between the 2 species. $D_{\mathrm{b}}$ tended to decrease with experiment duration in Abra nitida and to increase with experiment duration in A. ovata. This discrepancy probably resulted from the different feeding strategies of these 2 species. In A. nitida, the increase in feeding activity mostly results from an increase in feeding intensity (Grémare et al. 2004). During our experiments sediment reworking rates were maximal immediately after food addition, which confirmed the ability of this species to rapidly exploit food pulses resulting from the sedimentation of phytoplanktonic blooms (Grémare et al. 2004). Conversely, increase in feeding activity in $A$. ovata mostly resulted from an increase in the amount of time devoted to feeding. This may explain why during our experiments sediment reworking rates increased progressively with time. In any case, such differences in temporal changes in sediment reworking rates underline the importance of carefully defining the duration of sediment reworking experiments, which are often fixed a priori in classical luminophore experiments (Gérino et al. 1994, François et al. 1998, 2002, Mugnai et al. 2003).

\section{CONCLUSIONS}

The combined utilisation of thin aquaria, luminophores and image analysis techniques proved efficient in visualising, characterising and quantifying sediment reworking processes at different time and spatial scales, information that is required to precisely study the behavioural ecology of infaunal benthic organisms. Our results showed that, despite being closely related, Abra ovata and A. nitida featured 2 distinct types of sediment reworking. These 2 species were efficient bioturbators, which resulted in a quick reduction of luminophore at the water-sediment interface and thus limited experimental duration. A. ovata and A. nitida featured 2 different responses to organic matter availability. These responses were coherent with recently described types of feeding activity in these 2 bivalves (Grémare et al. 2004). The experimental approach used during the present study allowed the assessment of sediment reworking at different spatial scales and for different vertical grid sizes. $D_{\mathrm{b}}$ values were strongly affected by these 2 parameters due to: (1) spatial heterogeneity associated with sediment reworking and (2) the magnitude of vertical grid sizes relative to concentration gradients. It was concluded that the sizes of cores (i.e. up to $50 \mathrm{~cm}^{2}$ ) most often used during classical luminophore experiments would be suitable to assess sediment reworking in the 2 tested species. Conversely, a vertical grid size of $0.5 \mathrm{~cm}$, which is commonly used during such experiments, would not be appropriate to assess sediment reworking in A. nitida, due to the thinness of the reworked sediment layer.

Acknowledgements. This work is part of the $\mathrm{PhD}$ thesis of O.M., who was supported by the French Ministère de l'Education de la Recherche et de la Technologie. It was carried out within the framework of the Programme National Environnement Côtier (AT MESO and Chantier Méditerranée NordOccidentale). We acknowledge the financial support of Naturalia and Biologia and of the Swedish Royal Academy. We also thank all the staff of the Kristineberg Marine Research Station for their assistance. Special thanks are due to Karl Norling for his help during part of the experiments. We also thank 3 anonymous referees for constructive suggestions which contributed significant improvements to this manuscript.

\section{LITERATURE CITED}

Aller RC (1982) The effects of macrobenthos on chemical properties of marine sediment and overlying water. In: McCall PL, Tevesz MJS (eds) Animal-sediment relations - the biogenic alteration of sediments. Topics in geobiology, Vol 2. Plenum Press, New York, p 53-102

Aller RC (1994) Bioturbation and remineralization of sedimentary organic matter: effects of redox oscillation. Chem Geol 114:331-345

Aller RC, Yingst JY (1985) Effects of the marine deposit-feeders Heteromastus filiformis (Polychaeta), Macoma balthica (Bivalvia), and Tellina texana (Bivalvia) on averaged sedimentary solute transport, reaction rates and microbial distributions. J Mar Res 43:615-645

Alperin MJ, Suayah IB, Benninger LK, Martens CS (2002) Modern organic carbon burial fluxes, recent sedimentation rates, and particle mixing rates from the upper continental slope near Cape Hatteras, North Carolina (USA). 
Deep-Sea Res Part II 49:4645-4665

Andersen FO, Kristensen E (1991) Effects of burrowing macrofauna on organic matter decomposition in coastal marine sediments. Symp Zool Soc Lond 63:69-88

Belgrano A, Lindahl O, Hernroth B (1999) North Atlantic Oscillation primary productivity and toxic phytoplankton in the Gullmar Fjord, Sweden (1985-1996). Proc R Soc B 266:425-430

Berg P, Rysgaard S, Funch P, Sejr MK (2001) Effects of bioturbation on solutes and solids in marine sediments. Aquat Microb Ecol 26:81-94

Biles CL, Paterson DM, Ford RB, Solan M, Raffaelli DG (2002) Bioturbation, ecosystem functioning and community structure. Hydrol Earth Syst Sci 6:999-1005

Boudreau BP (1986) Mathematics of tracer mixing in sediments. II. Non-local mixing and biological conveyor-belt phenomena. Am J Sci 286:199-238

Cochran JK (1985) Particle mixing rates in sediments of the eastern equatorial Pacific: evidence from ${ }^{210} \mathrm{~Pb},{ }^{239,}{ }^{240} \mathrm{Pu}$ and ${ }^{137} \mathrm{Cs}$ distributions at MANOP sites. Geochim Cosmochim Acta 49:1195-1210

Crank J (1975) The mathematics of diffusion. Oxford University Press, Oxford

Duchêne JC (2004) Early sediment recognition during larval settlement of Eupolymnia nebulosa (Polychaeta: Terebellidae). Mar Biol 145:79-85

Duchêne JC, Nozais C (1994) Light influence on larval emission and vertical swimming in the terebellid worm Eupolymnia nebulosa (Montagu, 1818). Mem Mus Natl Hist Nat Zool 162:405-412

Duchêne JC, Queiroga H (2001) Use of an intelligent CCD camera for the study of endogenous vertical migration rhythms in first zoeae of the crab Carcinus maenas. Mar Biol 139:901-909

Duchêne JC, Jordana E, Charles F, Grémare A, Amouroux JM (2000) Experimental study of filtration activity in Ditrupa arietina (Annelida Polychaeta) using an automated image analysis system. Oceanol Acta 23:805-817

François F, Poggiale JC, Durbec JP, Stora G (1997) A new approach for the modelling of sediment reworking induced by a macrobenthic community. Acta Biotheor 45: 295-319

François F, Dalegre K, Gilbert F, Stora G (1998) Specific variability within functional groups: study of the sediment reworking of two Veneridae bivalves, Ruditapes decussatus and Venerupis aurea. CR Acad Sci Ser III Sci Vie 322: 339-345

François F, Poggiale JC, Durbec JP, Stora G (2001) A new model of bioturbation for a functional approach to sediment reworking resulting from macrobenthic communities. In: Aller JY, Woodin SA, Aller RC (eds) Organism-sediment interactions. University of South Carolina Press, Columbia, SC, p 75-88

Francois F, Gérino M, Stora G, Durbec JP, Poggiale JC (2002) Functional approach to sediment reworking by galleryforming macrobenthic organisms: modeling and application with the polychaete Nereis diversicolor. Mar Ecol Prog Ser 229:127-136

Fuller CC, Van Geen A, Baskaran M, Anima R (1999) Sediment chronology in San Francisco Bay, California, defined by ${ }^{210} \mathrm{~Pb},{ }^{234} \mathrm{Th},{ }^{137} \mathrm{Cs}$, and ${ }^{239,}{ }^{240} \mathrm{Pu}$. Mar Chem $64: 7-27$

Furukawa Y, Bentley SJ, Lavoie DL (2001) Bioirrigation modeling in experimental benthic mesocosms. J Mar Res 59:417-452

Gérino M (1990) The effects of bioturbation on particle redistribution in Mediterranean coastal sediment. Preliminary result. Hydrobiologia 207:251-258
Gérino M, Stora G, Durbec JP (1994) Quantitative estimation of biodiffusive and bioadvective sediment mixing: in situ experimental approach. Oceanol Acta 17(5):547-554

Gérino M, Aller RC, Lee C, Cochran JK, Aller JY, Green MA, Hirschberg D (1998) Comparison of different tracers and methods used to quantify bioturbation during a spring bloom: 234-Thorium, luminophores and chlorophyll $a$. Estuar Coast Shelf Sci 46:531-547

Gilbert F, Bonin P, Stora G (1995) Effect of bioturbation on denitrification in a marine sediment from the West Mediterranean littoral. Hydrobiologia 304:49-58

Gilbert F, Hulth S, Stroemberg N, Ringdahl K, Poggiale JC (2003) 2-D optical quantification of particle reworking activities in marine surface sediments. J Exp Mar Biol Ecol 285/286:251-263

Goldberg ED, Koide M (1962) Geochronological studies of deep sea sediments by the ionium/thorium method. Geochim Cosmochim Acta 26:417-450

Gray JS (1974) Animal-sediment relationships. Oceanogr Mar Biol Annu Rev 12:223-261

Green MA, Aller RC, Cochran JK, Lee C, Aller JY (2002) Bioturbation in shelf/slope sediments off Cape Hatteras, North Carolina: the use of ${ }^{234} \mathrm{Th}, \mathrm{Chl}-\mathrm{a}$, and $\mathrm{Br}$ to evaluate rates of particle and solute transport. Deep-Sea Res Part II 49:4627-4644

Grémare A, Amouroux JM, Charles F, Dinet A and 7 others (1997) Temporal changes in the biochemical composition and nutritional value of the particulate organic matter available to surface deposit-feeders: a two year study. Mar Ecol Prog Ser 150:195-206

Grémare A, Duchêne JC, Rosenberg R, David E, Desmalades $M$ (2004) Feeding behaviour and functional response of Abra ovata and $A$. nitida compared by image analysis. Mar Ecol Prog Ser 267:195-208

Guelorget O, Mayere C (1981) Growth, biomass and production of Abra ovata in a Mediterranean Lagoon, the Etang du Prevost at Palavas (Herault, France). J Rech Oceanogr 6:23-41

Guinasso NL, Schink DR (1975) Quantitative estimates of biological mixing rates in abyssal sediments. J Geophys Res 80:3032-3043

Hassler C (1998) Using Tetraselmis sp. (PLY429) as a food for hard clams: one hatchery's experiences. J Shellfish Res 17: 355-356

Hollertz K, Duchêne JC (2001) Burrowing behaviour and sediment reworking in the heart urchin Brissopsis lyrifera Forbes (Spatangoida). Mar Biol 139:951-957

Jordana E, Duchêne JC, Charles F, Grémare A, Amouroux JM (2000) Experimental study of suspension-feeding activity in the serpulid polychaete Ditrupa arietina (O.F. Müller). J Exp Mar Biol Ecol 252:57-74

Josefson AB (1982) Regulation of population size, growth, and production of a deposit-feeding bivalve: a long-term field study of three deep-water populations off the Swedish west coast. J Exp Mar Biol Ecol 59:125-150

Kniskern TA, Kuehl SA (2003) Spatial and temporal variability of seabed disturbance in the York River subestuary. Estuar Coast Shelf Sci 58:37-55

Krezoski JR, Robbins JA, White DS (1984) Dual radiotracer measurement of zoobenthos-mediated solute and particle transport in freshwater sediments. J Geophys Res 89: 7937-7947

Lecroart P, Schmidt S, Jouanneau JM, Weber O (2005) Be-7 and Th-234 as tracers of sediment mixing on seasonal time scale at the water-sediment interface of the Thau Lagoon. Radioprotection 40:661-667

Lecroart P, Schmidt S, Jouanneau JM (in press) Numerical 
estimation of the error of the biodiffusion coefficient in coastal sediments. Estuar Coast Shelf Sci

Lee H, Swartz RC (1980) Biological processes affecting the distribution of pollutants in marine sediments, Part II. Biodeposition and bioturbation. In: Baker RA (ed) Contaminants and sediments, Vol 2. Analysis, chemistry, biology. Ann Arbor Science Publishers, Ann Arbor, MI, p 555-606

Lindahl O (1988) Sedimentation and oxygen consumption below sill level in the Gullmar Fjord, Sweden. In: Wassmann P, Heiskanen AS (eds) Sediment trap studies in the Nordic countries, Vol 1: Workshop proceedings. Helsinki University Press, Helsinki, p 149-159

Lohrer AM, Thrush SF, Gibbs MM (2004) Bioturbators enhance ecosystem function through complex biogeochemical interactions. Nature 431:1092-1095

Mahaut ML, Graf G (1987) A luminophore tracer technique for bioturbation studies. Oceanol Acta 10:323-328

Meadows PS, Meadows A (1991) The geotechnical and geochemical implications of bioturbation in marine sedimentary ecosystems. Symp Zool Soc Lond 63:157-181

Mermillod-Blondin F, François-Carcaillet F, Rosenberg R (2005) Biodiversity of benthic invertebrates and organic matter processing in shallow marine sediments: an experimental study. J Exp Mar Biol Ecol 315:187-209

Meysman FJR, Boudreau BP, Middelburg JJ (2003) Relations between local, nonlocal, discrete and continuous models of bioturbation. J Mar Res 61:391-410

Millet B, Guelorget O (1994) Spatial and seasonal variability in the relationships between benthic communities and physical environment in a lagoon ecosystem. Mar Ecol Prog Ser 108:161-174

Mugnai C, Gérino M, Frignani M, Sauvage S, Bellucci LG (2003) Bioturbation experiments in the Venice Lagoon. Hydrobiologia 494:245-250

Olmez I, Pink FX, Wheatcroft RA (1994) New particlelabelling technique for use in biological and physical sediment transport studies. Environ Sci Technol 28: $1487-1490$

Ouellette D, Desrosiers G, Gagne JP, Gilbert F, Poggiale JC, Blier PU, Stora G (2004) Effects of temperature on in vitro sediment reworking processes by a gallery biodiffusor, the polychaete Neanthes virens. Mar Ecol Prog Ser 266: 185- 195

Rhoads DC (1974) Organism-sediment relations on the muddy sea floor. Oceanogr Mar Biol Annu Rev 12:263-300

Rhoads DC, Boyer LF (1982) The effects of marine benthos on physical properties of sediments. A successional perspective. In: McCall PL, Tevesz MJS (eds) Animal-sediment relations - the biogenic alteration of sediments. Topics in geobiology, Vol 2. Plenum Press, New York, p 3-52

Rice DL (1986) Early diagenesis in bioadvective sediments: relationships between the diagenesis of beryllium-7, sediment reworking rates, and the abundance of conveyorbelt deposit-feeders. J Mar Res 44:149-184

Robbins JA (1982) Stratigraphic and dynamic effects of sediment reworking by Great Lakes zoobenthos. Hydrobiologia 92:611-622

Robbins JA, Husby-Coupland K, White DS (1984) Precise radiotracer measurement of the rate of sediment reworking by Stylochrilus heringianus and the effects of variable dissolved oxygen concentrations. J Gt Lakes Res 10: $335-347$

Rowden AA, Jago CF, Jones SE (1998) Influence of benthic macrofauna on the geotechnical and geophysical properties of surficial sediment, North Sea. Cont Shelf Res 18: $1347-1363$

Schmidt S, Jouanneau JM, Weber O, Lecroart P, Radakovitch O, Gilbert F, Jézequel D, Rabouille C (in press) Sediment dynamics at the water-sediment interface of the Thau Lagoon (south France): from seasonal to century time scales using radiogenic and cosmogenic nuclides. Estuar Coast Shelf Sci

Sharma P, Gardner LR, Moore WS, Bollinger MS (1987) Sedimentation and bioturbation in a salt marsh as revealed by ${ }^{210} \mathrm{~Pb},{ }^{137} \mathrm{Cs}$, and ${ }^{7} \mathrm{Be}$ studies. Limnol Oceanogr 32:313-326

Smith JN, Boudreau BP, Noshkin V (1986) Plutonium and ${ }^{210} \mathrm{~Pb}$ distributions in northeast Atlantic sediments subsurface anomalies caused by non-local mixing. Earth Planet Sci Lett 81(1):15-28

Soetaert K, Herman PMJ, Middelburg JJ, Heip CHR, de Stiger HS, van Weering TCE, Eping E, Helder W (1996) Modelling $210 \mathrm{~Pb}$-derived mixing activity in ocean margin sediments: diffusive versus nonlocal mixing. J Mar Res 54: $1207-1227$

Solan M, Cardinale BJ, Downing AL, Engelhardt KAM, Ruesink JL, Srivastava DS (2004a) Extinction and ecosystem function in the marine benthos. Science 306: $1177-1180$

Solan M, Wigham BD, Hudson IR, Kennedy R, Coulon $\mathrm{CH}_{\text {, }}$ Norling K, Nilsson HC, Rosenberg R (2004b) In situ quantification of bioturbation using time-lapse fluorescent sediment profile imaging (f-SPI), luminophore tracers and model simulation. Mar Ecol Prog Ser 271:1-12

Sun M, Aller RC, Lee C (1991) Early diagenesis of chlorophyll-a in Long Island Sound sediments: a measure of carbon flux and particle reworking. J Mar Res 49:379-401

Thomson J, Brown L, Nixon S, Cook GT, MacKenzie AB (2000) Bioturbation and Holocene sediment accumulation fluxes in the north-east Atlantic Ocean (Benthic Boundary Layer experiment sites). Mar Geol 169:21-39

Tromp TK, Van Cappellen P, Key RM (1995) A global model for the early diagenesis of organic carbon and organic phosphorus in marine sediments. Geochim Cosmochim Acta 59:1259-1284

Wheatcroft RA (1992) Experimental tests for particle sizedependent bioturbation in the deep ocean. Limnol Oceanogr 37:90-104

Wheatcroft RA, Martin WR (1996) Spatial variation in shortterm ${ }^{234} \mathrm{Th}$ sediment bioturbation intensity along an organic-carbon gradient. J Mar Res 54:763-792

Wheatcroft RA, Olmez I, Pink FX (1994) Particle bioturbation in Massachusetts Bay: preliminary results using a new deliberate tracer technique. J Mar Res 52:1129-1150

White DS, Klahr PC, Robbins JA (1987) Effects of temperature and density on sediment reworking by Stylodrilus heringianus (Oligochaeta: Lumbriculidae). J Gt Lakes Res 13:147-156

Widdows J, Blauw A, Heip CHR, Herman PMJ and 6 others (2004) Role of physical and biological processes in sediment dynamics of a tidal flat in Westerschelde Estuary, SW Netherlands. Mar Ecol Prog Ser 274:41-56

Wikander PB (1980) Biometry and behavior in Abra nitida (Mueller) and A. longigallus (Scacchi) (Bivalvia, Tellinacea). Sarsia 65:255-268

Wikander PB (1981) Quantitative aspects of deposit feeding in Abra nitida (Mueller) and A. longigallus (Scacchi) (Bivalvia, Tellinacea). Sarsia 66:35-48

Submitted: July 7, 2005; Accepted: December 22, 2005

Proofs received from author(s): July 11, 2006 